\title{
THE DRAINAGE OF THE RIVER OUSE BASIN.
}

By E. G. CROCKER, Member, of ELY.

The River Ouse is perhaps one of the most interesting of the rivers in the Eastern Counties from an engineering standpoint. The manner in which it has been confined between banks, and the reclamation and drainage of the Fen lands through which it flows, are to-day a monument to the perseverance and industry of the people who in former years carried out these, at that time, great works. It is not intended, however, to deal with an historical account of the construction of these works but to describe them briefly as they exist to-day, together with some detail of the work necessary to maintain them in a satisfactory state, and to give particulars of the drainage of some of the Fens.

General Description.-The River Ouse is the outfall for the drainage of $1,936,000$ acres of land; the western branch of the river with its principal tributaries-the Tove, the Ouzel, the Ivel, the Kym and the Alconbury Brook-drain an area of 760,873 acres through the Hundred Feet River; the eastern branch of the river [The I.Mech.E.] 
- MAP OF-

\section{- THE DRAINAGE BASIN -}

二oF-

\section{THE RIVER OUSE}

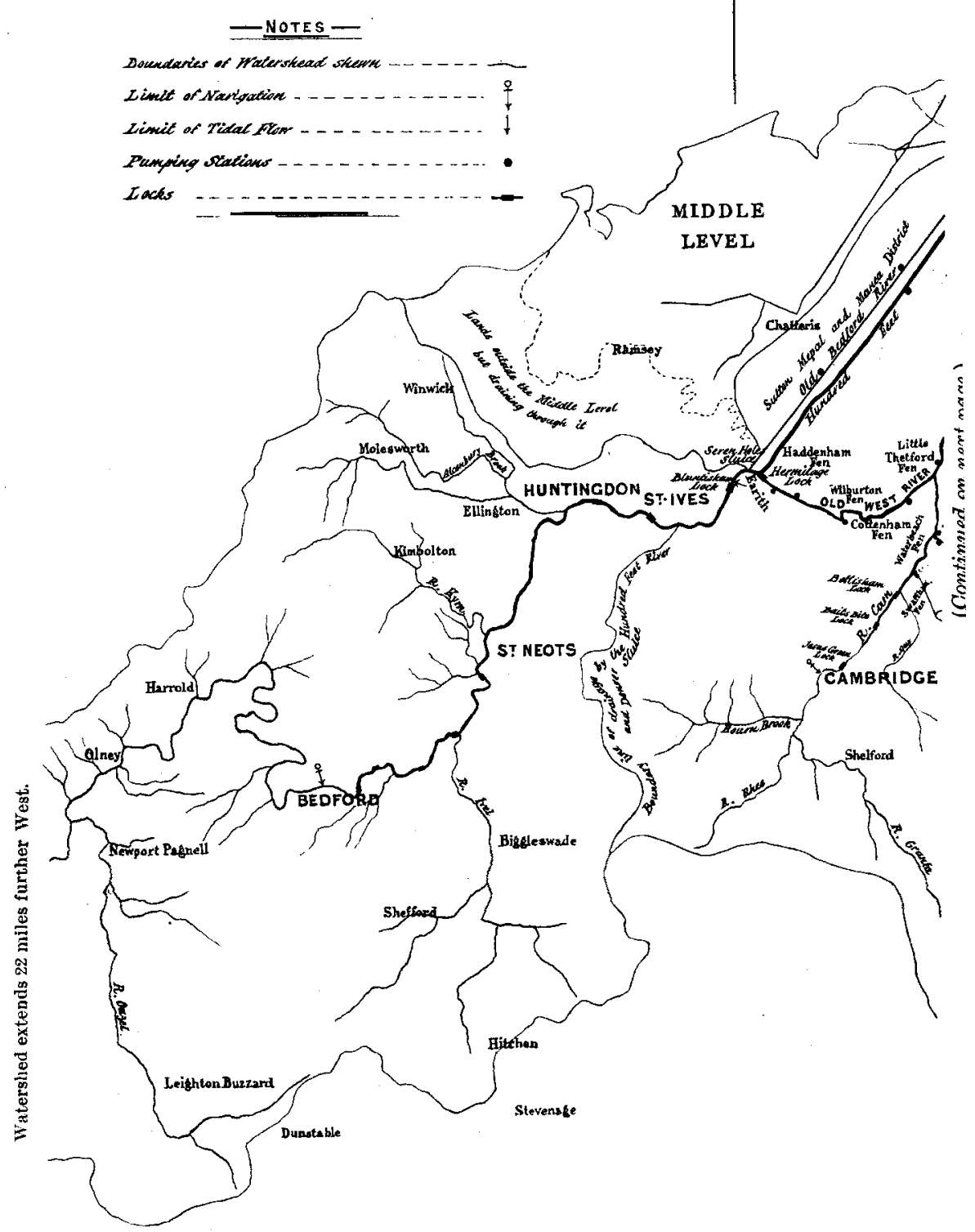



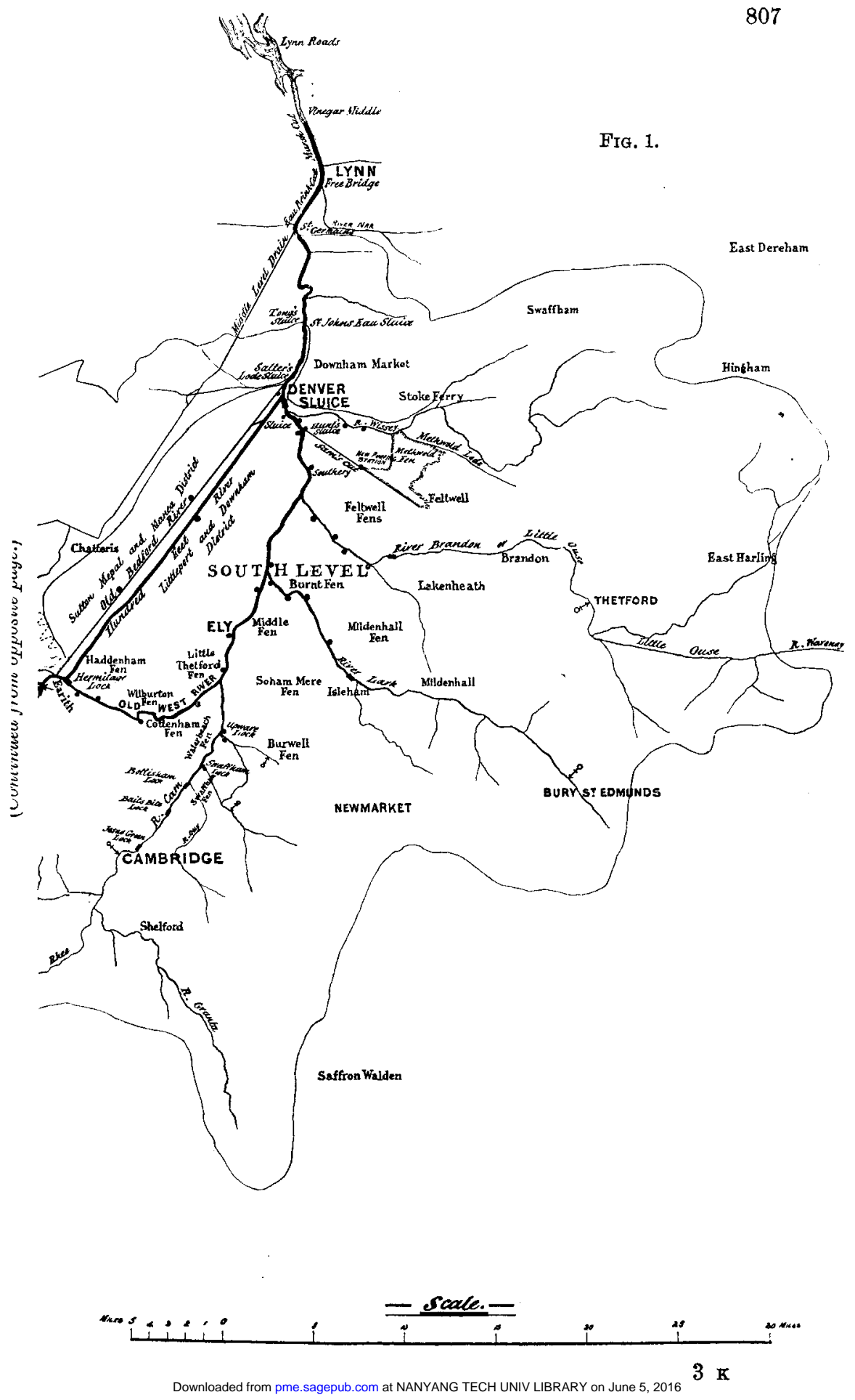
with its principal tributaries - the Cam, the Lark, the Brandon and the Wissey-drain an area of 884,338 acres through Denver Sluice; between Denver Sluice and St. Germains the River Ouse receives the drainage of 52,424 acres; at St. Germains it receives the drainage of 154,515 acres through the Middle Level Sluice, and at King's Lynn the drainage of 83,840 acres from the River Nar.

The eastern branch of the river is of no great interest from the Fenland drainage point of view ; the portion, however, from Earith to Denver, known as the Hundred Feet River, is an artificially embanked cut, 21 miles in length, constructed by the Honourable Bedford Level Corporation to shorten the course to the sea and thus relieve the river passing through the more valuable Fen lands from the enormous volume of flood water brought down by this branch of the river.

The works which will principally be described are those in the eastern branch of the river above Denver Sluice. The area discharging from the Middle Level is fully dealt with by Mr. Grantham, and the works in the River Nar and other portions are similar to those which will be described. The map, Fig. 1 (pages 806-7), shows the river with its principal tributaries, the positions of the locks, chief pumping stations, and other information.

The Tidal Portion of the River.-Commencing at the mouth of the Ouse and proceeding upwards the stone training banks are passed first, and then the entrance channel leading to King's Lynn docks, and so through the Eau Brink Cut (an artificially embanked cut about 4 miles in length) to the sluice from which the Middle Level Drainage discharges and so on to Denver Sluice which will be described later. The important works in this part of the river are the maintenance of the banks and of the channel to the sea. The repairing, by means of faggots, of the banks of the Eau Brink Cut is shown in Fig. 2, Plate 17, and gives a clear view of the method of doing this work; 30,000 faggots are used in the repair of these banks annually, and the latter are maintained in a very good state, although, unfortunately, the same cannot be said of the 
banks of some other portions of the river. The maintenance of the channel to the sea is exceedingly important, the free discharge of the flood waters being vital; from observations taken, it has been found that low water of spring tides does not now fall to as low a level as in former years, and investigations are at present proceeding to ascertain the cause of this, cross-sections of the river from St. Germains to the sea having been taken. The problem of drainage thus brought about is very interesting, and one calling for very careful consideration; conditions of drainage have, however, so altered during recent years that with no improvement works in the river, it is in the exact condition that one would expect to arise. The lowering of this low-water level will necessitate considerable dredging and enlarging of the river channel, and even so the low level of former years cannot be expected to be obtained.

The authority controlling the Eau Brink Cut has also to maintain the free bridge over the river at King's Lynn, built in the year 1873 and shown in Fig. 3, Plate 17. This bridge is of interest in that it is a five-span continuous girder bridge, the spans being two of 70 feet and three of 120 feet. The deflection of this bridge under existing loads is very excessive, and its reconstruction will have to be carried out in the near future, as it takes considerable traffic on the main road from King's Lynn to Wisbech.

Denver Sluice.-This is the most important work in the River Ouse, as on it depends the safety of the whole of the Fens in the South Level. Its duties are threefold: (1) To prevent the tidal waters from passing up the river; (2) to discharge flood waters; and (3) to maintain the water in the river at the normal navigation level of 4.92 feet above Ordnance datum. The importance of the sea-gates being maintained in proper working order will be apparent when it is remembered that the level of the tops of the river banks is from 12 to 13 feet above O.D., whilst an ordinary spring tide rises to 14 feet above O.D. at the sluice, the highest recorded tide being $17 \cdot 51$ feet above O.D., so that should 
Frg. 4.-Denver Sluice.

Constructed in 1832 from the design of John Rennie dated 1830.

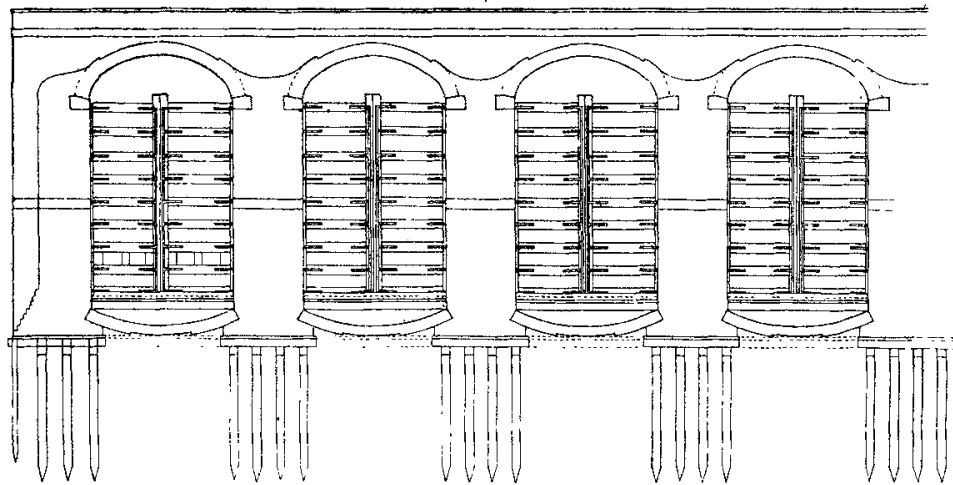

SECTIONAL ELEVATION

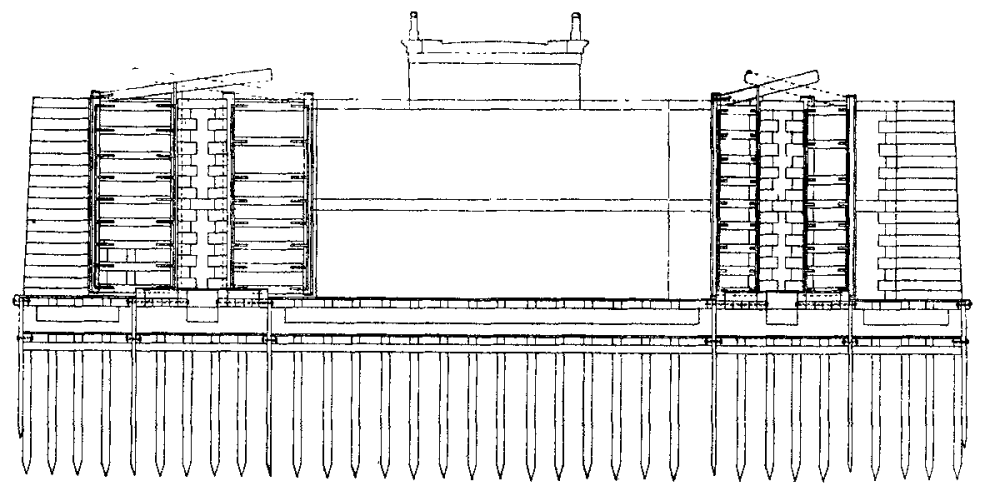

LONGITUDINAL SECTION OF LOCK

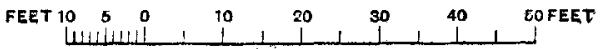


Fia. 4.-Denver Sluice.

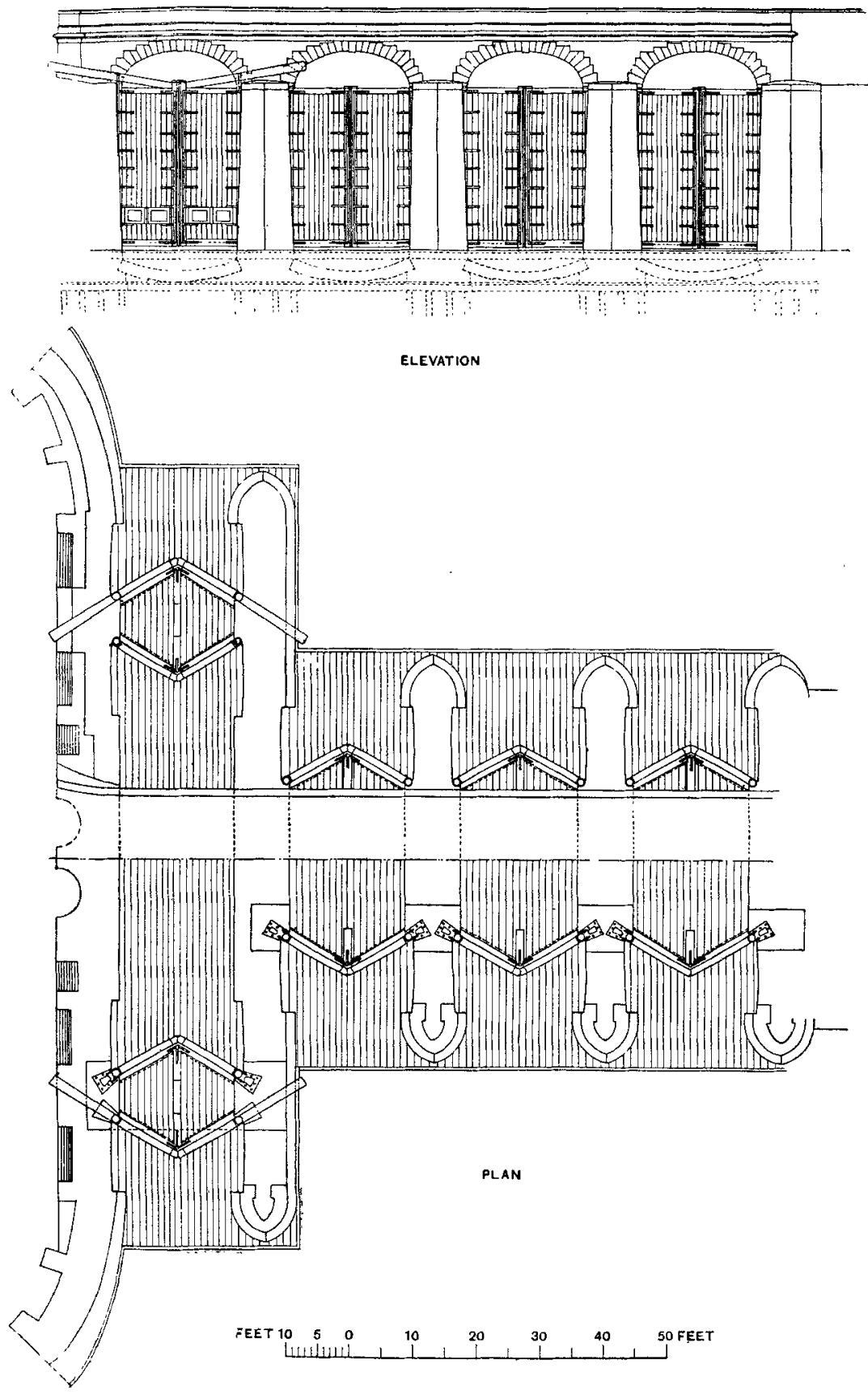


anything occur to prevent these gates closing on a spring tide, practically the whole of the Fens of the South Level would be flooded. On its discharging capacity depends the prevention of the flooding of the Fens in flood time, this discharge varying with every tide and with the different heights of the river water, and of low water on the sea side.

A reliable way of arriving at the actual discharge in a given period is to take the average rainfall over the drainage area and the time that the doors are open. The period from the third week in August 1912, when the heavy rains of last year commenced, to the end of April 1913, will give a good illustration of the discharge of the sluice. During this period it is calculated that, taking an average over the area drained by the sluice, namely, 884,338 acres, 25 inches of rain fell (equal to $2,010,876,000$ tons). The whole of this water eventually finds its way to the sluice with the exception of that lost by evaporation, which varies according to the time of year; 10 per cent. is considered to be more than ample for the period under review. This gives a quantity of $1,809,788,400$ tons to be discharged by the sluice.

The doors were open as follows:-

$$
\begin{array}{rrr}
2 \text { eyes. } & 3 \text { eyes. } & 4 \text { eyes. } \\
60 \text { days, } & 23 \text { days, } & 157 \text { days, }
\end{array}
$$

or, say, equal to 204 days with all the four eyes open; and as the time which the doors remain open varies from 8 hours on a spring tide to 12 hours on a neap tide, 10 hours per tide may be taken as a fair average of the time of discharge per tide; this gives 4,080 hours, or 244,800 minutes, during which time $1,809,788,400$ tons of water have to be discharged, which is equal to 7,413 tons per minute.

The present sluice was constructed in 1832, and consists of a navigation lock 74 feet in length between gates with a width of 18 feet; it is fitted with double gates so as to permit of the passage of vessels at any state of different water-levels, and three drainage eyes 17 feet 6 inches in width fitted with sea- and river-gates, the level of the sills being in all cases $8 \cdot 24$ feet below Ordnance datum. The construction of the sluice and of the doors is shown on 
FIG. 5.-Denver Sluice. Details of Gates.
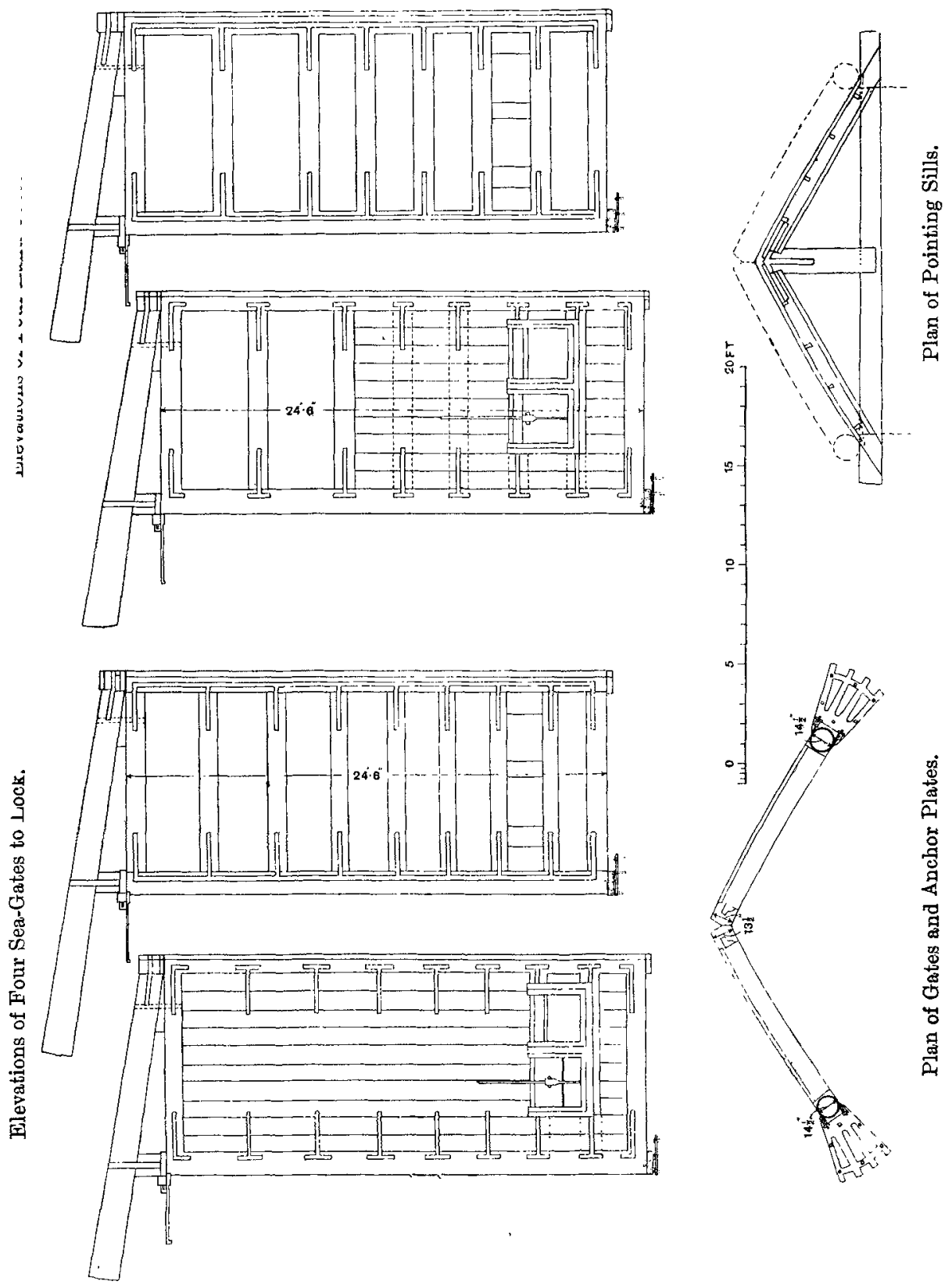
Figs. 4 and 5 (pages 810-1, and 813), and calls for no special comment except that particular care was taken in piling and sheet piling the foundations, the two previous sluices showing the necessity of this, as they were both blown up. The gates are constructed of English oak, with framing strongly strapped together by wrought-iron straps, the sheeting of the gates being of pitch pine. One pair of gates was taken out last summer for examination and for repairs to the slacker frames which are of cast-iron and were broken, and the gates were found to be in excellent condition after being in for twenty-six years; it is proposed to take out the whole of the gates for examination and overhaul during the next two summers. The construction of the gates, anchorages and footsteps of the heel posts is shown on Fig. 5. Fig. 6, Plate 17, shows the sluice from the sea side, and Fig. 7 shows it from the river side.

Navigation.-Having referred to the navigation lock at Denver Sluice, it would perhaps be well now to say something on the generally accredited very important subject of inland navigation, although decried by some as a matter which should receive no consideration, as it has diminished to such a large extent.

The lock at Denver Sluice is the one nearest to the sea and between it and Cambridge there are three only, namely, at Bottisham, Baites Bite, and Jesus Green, so that the navigation between the port of King's Lynn and Cambridge-a distance of 50 miles-is not impeded by many locks.

A lock at the Hermitage, by Earith, connects the River West with the top of the Hundred Feet River and so connects up the eastern and western branches of the Ouse. The first lock from the sea on this western branch is at Bluntisham, a distance of 42 miles; the locks and waterways on this branch of the river are in a very neglected state, but there is, however, a proposal under consideration by the Town Council of Bedford to endeavour to bring this navigation up to present requirements.

There are locks at Swaflham and Upware, connecting with tributaries of the Cam; the erection of a new pair of gates at Swaffham Lock, the repairing of the sills and other work, is 
shown in Figs. 8 and 9, Plate 18, taken on the 6th of June. These gates are similar in construction to those at Denver Sluice, but are 15 feet in height.

The first lock on the River Lark is at Isleham and on the River Brandon at Cross Waters, all of which locks are shown on the general drawing of the Ouse Basin, Fig. 1 (pages 806-7).

It will thus be seen that the River Ouse is one easily navigated, and which, at comparatively small cost, could be brought up to modern requirements and with every facility for the conveyance and handling of all classes of traffic. If these facilities were provided, there could be no doubt that the traftic would greatly increase and a considerable revenue be derived therefrom. The traffic has increased during the last few years, showing that, in spite of the lack of facilities, carriage of waterborne goods has not altogether ceased.

At the mouth of the River Ouse is situated the port of King's Lynn which, although not one of the leading ports in the Kingdom, is a port of some consideration, whilst it is the nearest to the manufacturing districts of the Midlands. The opening up of efficient waterways between these districts and King's Lynn would therefore be most advantageous to both, and to the towns along the route, whilst the authorities controlling the rivers would materially benefit by the increased tolls which would become available for expenditure on the improvement of the navigation, and consequently the improvement of the drainage which is of the greatest importance. The carrying out of any efficient scheme for the improvement of navigation will however be most difficult, the authorities controlling the river being so very numerous, and thus it is unlikely that any progress will be made in this direction without Government assistance.

Banks. -The banks protecting the fens from submersion have been in nearly all cases constructed of silt and soil obtained from the river and adjacent land; such banks of necessity leak considerably during high waters, and in many places it has been found necessary to put in a puddle core and in other places to put a 
gault facing to them, whilst some banks at the present time soak considerably, entailing a great deal of extra pumping. The level of the Fen lands varies from 5 feet above O.D. in Swaffham Fen to O.D. in Southery Fen, navigation water-level being $4 \cdot 92$ above O.D. and an average flood level 10.00 above O.D., whilst the highest recorded flood level is $11 \cdot 76$ at Denver Sluice and approximately 1 foot higher at Ely. The tops of the banks have therefore to be maintained at a level of not less than 12 to 13 above O.D., and as the banks sink from 1 inch to 2 inches each year, they have to be periodically topped.

Most of the Fen Commissions who have to maintain these banks top them with gault obtained from the Roswell Hill Quarry, situated near Ely, and Fig. 10, Plate 18, shows the gault being obtained and loaded into lighters for transport. A good example of the work of strengthening a river bank is that now being done by the Mildenhall Fen Commission to the River Lark bank. It is estimated that the land in this fen has sunk 3 to 4 feet since the banks were made, and thus they have to withstand an increased head of water in flood time. The bank when made was built on a bed of chalk stones about 9 inches in thickness, through which the water has always percolated to an undesirable extent, and in recent years, owing to the increased head of water, to such an extent that it was felt some remedial measure must be carried out. The existing bank and the work now being executed is shown on a cross-section of the bank, Fig. 11 (page 817). A trench is opened at the river toe of the bank, taken through the layer of chalk stones into the original moor below and then filled with well-rammed puddle; the bank is faced with gault to the top, the gault being obtained from the Roswell Hill Quarry 8 miles distant. It is proposed at a later period to make up the back of the bank with dredgings from the river so as to give it increased stability. Fig. 12, Plate 18, shows this work in progress.

The heavy rains at the end of last August were unprecedented, and caused immense damage in the Eastern Counties; the district of the South Level, however, escaped without any very great disaster, one bank only, that at Hockwold, giving way. This bank 
was a moor and silt bank which had been protected at the top with chalk, then made up with soil and again topped with chalk. The sinking of the bank took the first layer of top chalk down to the level of the foreshore, and, under the head of flood water, the water entered this chalk stratum; the bank, being unable to withstand the hydrostatic pressure, was turned completely over. Figs. 13 to 16 , Plate 19, show the water rushing from the river into the $F e n$, the deep hole, 12 to 15 feet in depth, scoured out on the line of bank by the rush of water, the temporary sand-bag bank and the completed clay bank. After some little delay in arriving at a decision, the work of reconstructing the bank was commenced on the 13th November 1912, 440 tons of gault being conveyed from the Roswell Hill Quarry, 18 miles distant, up to Christmas Day by the one gang of lighters then available. Immediately after Christmas, however, twelve lighters, each carrying 20 tons, were put on this work, and 1,488 tons were transported to the bank in seventeen days, the cost of quarrying, loading and transport being $2 s$. $1 \frac{1}{4} d$. per ton, the smaller amount taken by the small gang costing 2s. $8 \frac{1}{4} d$. per ton. The

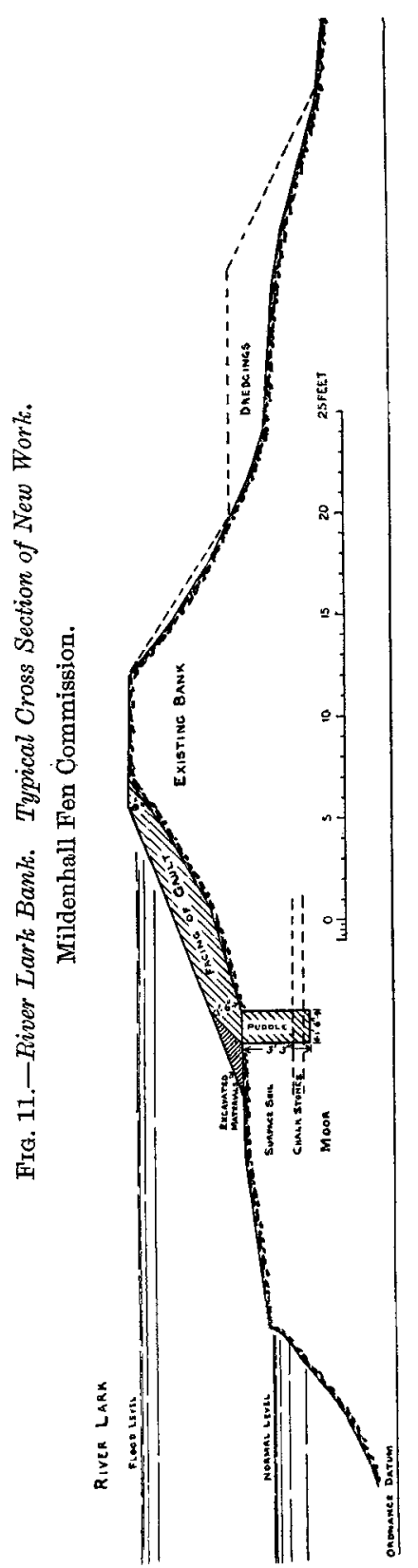


gault was unloaded just below the breach, a 2-foot portable railway ( 300 to 400 yards in length) being laid from the unloading berth to the breach; the materials were unloaded into tip-wagons and so conveyed to the site of the breach. The cost of conveying and depositing the materials after unloading was approximately $4 d$. per ton.

Dredging.-Fig. 17, Plate 20, shows a non-propelling bucketdredger at work in the River West; this vessel is 52 feet in length, 12 feet 6 inches beam and 3 feet draught. The boiler is an ordinary marine boiler, 4 feet in diameter by 5 feet 9 inches in length, the working pressure being $50 \mathrm{lb}$. per square inch. The engine is a horizontal single-cylinder engine, 10 inches diameter cylinder by 18 inches stroke, running at 90 revolutions per minute, set athwart the vessel, the crank-shaft being directly coupled to the main longitudinal driving shaft, from which the mooring winch and tumbler are driven in the usual way by shafting and gearing. The dredger is capable of dredging to a depth of 14 feet, discharging 120 cubic yards per hour under favourable conditions. A conveyor shoot is shown fitted, delivering the spoil on to the river side; it is constructed of pitch-pine timbers trussed to form the sides, with a curved sheet-steel bottom. The scoops conveying the spoil are of English elm 18 inches in width, fastened to a double shearsteel chain $8 \frac{3}{8}$ inches pitch; they are fitted to every fourth link. The conveyor chain is driven by a driving chain from a countershaft on deck, which is driven from the main shafting by bevel gearing and a short vertical shaft. This dredger is also arranged for delivering into barges. The dredger is a very old one, and does not comply with present ideas of an economical machine, but the cost of dredging, however, compares very favourably with modern dredgers. The cost of the work on which the vessel is now engaged works out at slightly over $2 \frac{1}{8} d$. per cubic yard, including all labour, coal, stores and repairs, but exclusive of any allowance for depreciation or interest on capital. Another dredger of similar design is at work just above Denver Sluice, but in this case the spoil has to be loaded into barges, transported a distance $\frac{1}{4}$ mile 
and upwards, and then unloaded on to the banks, considerably adding to the cost, which amounts to approximately $9 d$. per cubic yard.

It is anticipated that a large amount of dredging will have to be executed in the near future, and the purchase of a suction dredger has been recommended for this work so that the spoil can be deposited most economically at the back of the banks where it is most required, irrespective of the width of the river, height of bank, or reasonable distance it may have to be conveyed. Some opposition is being offered to a dredger of this type on the ground that a considerable volume of water will thus be put into the Fens, but as large quantities are now let in during the summer months for irrigation purposes the objection hardly seems a reasonable one, although in wet weather at flood times it might be of considerable moment. The principal dredging is, however, carried out during the summer months, and should it be necessary to continue dredging during continuous wet weather, it would be a simple matter to arrange for removing the water thus put into the Fens.

Weed-Cutting.-The weeds in the rivers have to be cut during the summer months, twice in the main rivers and as many as four or five times in the smaller ones; the weeds in the River Brandon grow so rapidly and so thickly that the water is at times held up as much as a foot by them. Fig. 18, Plate 20, and Fig. 19 (page 820) show the weed-cutter, and though the vessel might be adversely criticised by naval architects, she performs her work very effectively. The vessel was built under the supervision of the late Mr. George Carmichael, the machinery consisting of an ordinary 6 h.p. portable engine and boiler adapted to suit. The point of particular interest is the arrangement for imparting a short forward motion to the scythes, Fig. 20, in addition to the forward motion due to the vessel's progress; this is effected by a rocking lever having short arms to which the scythe-rods are attached. The rocking lever is worked by a rod driven from a small crank attached to the fly-wheel of the engine, and a forward travel of 6 inches at each revolution of 
the engine is thereby imparted. A diagrammatic sketch of this mechanism is shown below.

Fra. 19.-General Arrangement of Steam Weed-cutter Scythes.

The Honourable Bedford Level Corporation.

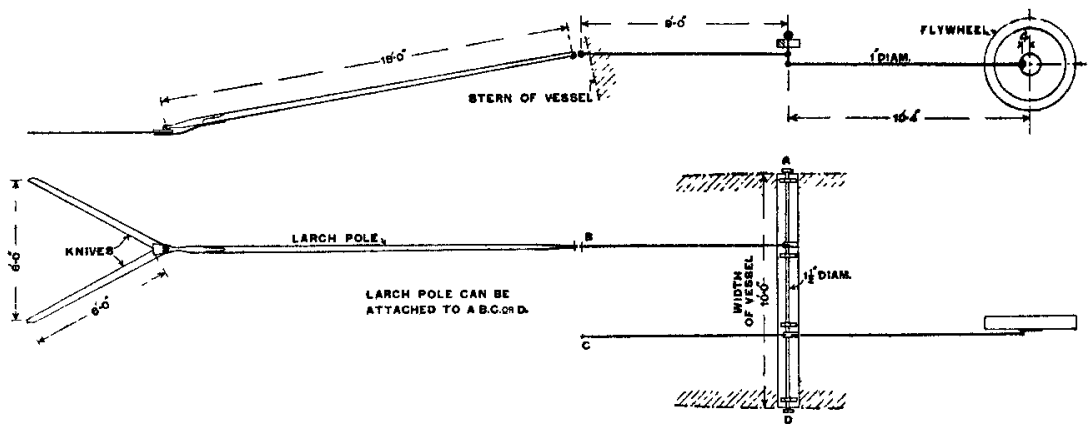

FIG. 20.-Weed-Cutter Scythes.

Elevation.
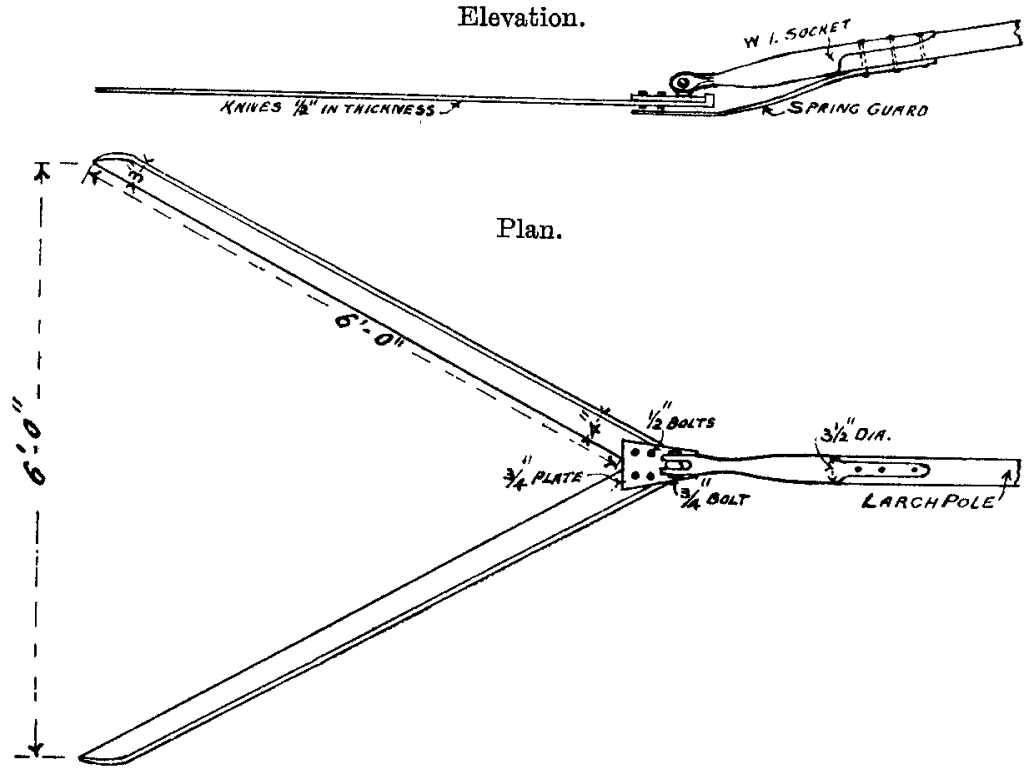
Drainage of the Fens.-Originally the whole of the Fens were drained by means of windmills driving scoop-wheels. Figs. 21, 22, Plate 20, and Figs. 23, 24, Plate 21, show the four mills which at one time drained the Middle Fen, and which are typical of the drainage mills which existed in all the Fens ; the present pumping plant of this Fen is fully described in Mr. Richard W. Allen's Paper.

As the Fens became more highly cultivated, it became necessary to have a more reliable source of power than the wind, and the next advance in Fen pumping machinery is illustrated by Fig. 26, Plate 22, which shows the beam engine at Southery belonging to the Feltwell New Fen Commissioners, and which drives a scoop-wheel 40 feet in diameter, shown in detail on Fig. 27 (page 822), which is a copy of the contract drawing. This engine is a double-acting engine erected in 1842 by Messrs. Headley and Hawthorn, of Newcastle, the diameter of the cylinder being 42 inches, length of stroke 72 inches, and number of revolutions per minute 24 , steam being supplied at a pressure of $12 \mathrm{lb}$. per square inch at the main stop-valve; the engine originally had tappet-valves which were removed in 1902, the Butterley Co. fitting one of their expansionvalves with variable cut-off. The engine is normally worked with steam cut-off at 18 inches, or $\frac{1}{4}$ stroke, but under heavy loads this is increased to 21 inches and sometimes more, the valve having a range of cut off from 9 inches to 54 inches. The engine is in excellent repair, and although there is much useful work in it yet, it is shortly to be replaced by modern machinery for reasons given hereafter. The excellent condition of the engine is no doubt in a great measure due to the fact that it has been driven by two men only since 1847-by Thomas Simpson Galley from 1847-1898, and since that date up to the present time by his son Thomas Galley.

The original scoop-wheel was removed in 1881 owing to the sinking of the Fen, and therefore, not being low enough to pump the water, it was replaced by the one shown on Fig. 27, made and erected by Messrs. James Watt and Co., London and Birmingham. This wheel is geared 6 to 1 , so that it makes four revolutions per minute when the engine is running at its normal speed of twenty-four revolutions per minute. On Fig. 26, Plate 22, is shown the gearing 
Fig. 27.-Southery Scoop-Wheel.

Feltwell New Fen Commission. Constructed in 1881 by Messrs. James Watt and Co, London and Birmingham.
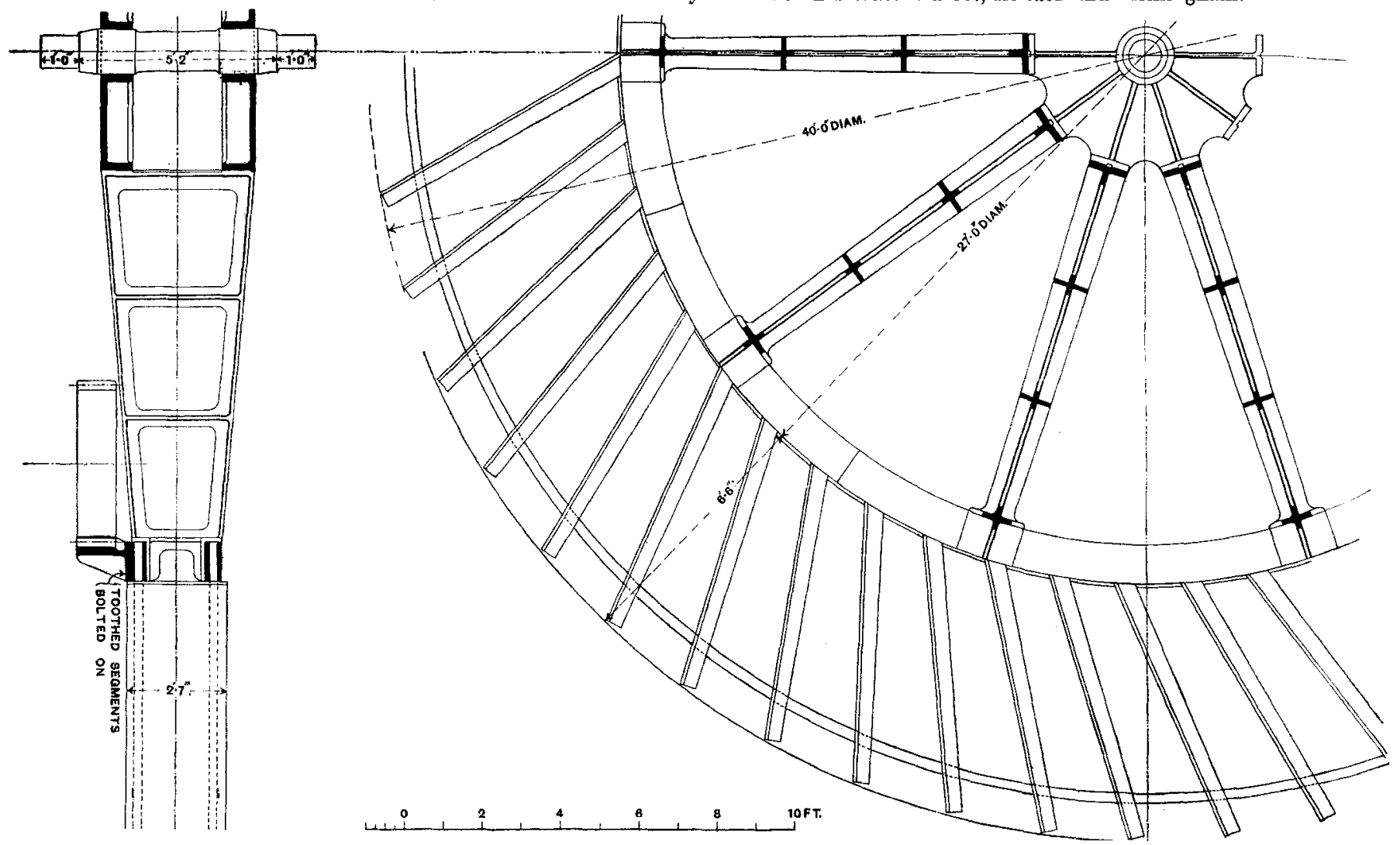

胥

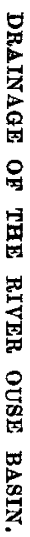

Downloaded from pme.sagepub.com at NANYANG TECH UNIV LIBRARY on June 5, 2016 
for raising the rising breast to this wheel, which is not shown on the drawing: this is worked by a hand-wheel in the engine-house, and the former is raised and lowered to suit the level of the water in the river; the head against which the wheel lifts varies from about 9 feet to 15 feet.

Owing to the continual sinking of the Fen, the bottom of the main drain is now about 3 feet below the bottom of the wheel-race; and as there is practically no fall on the main drains, the present plant cannot drain the Fen efficiently. Plans and specifications were prepared for a new installation, to consist of duplicate sets of compound inverted type enclosed forced-lubrication engines, directcoupled to twin impeller centrifugal pumps, delivering 100 tons of water each per minute against a maximum static head of 20 feet, steam being supplied from Babcock and Wilcox boilers. Tenders were invited for this plant, but, owing to the recent high prices, it was decided to postpone the installation and to proceed with the deepening and enlarging of the drains in the meantime.

The latest plant to be erected in the South Level of the Fens is that which has just been put down by the Methwold and Feltwell Drainage Board. The Methwold Fen until 1883 drained naturally through Sam's Cut, which discharges into the River Ouse at Hunt's Sluice; owing to the sinking of the Fen it became necessary to install artificial drainage, and in 1883 a dam with culverts was built across Sam's Cut at Hunt's Sluice, and an engine and pump erected. The culverts are, one for the pump discharge, closed by a self-closing tide-gate hung on gun-metal bearings, and the other, to permit of natural drainage when the levels of the waters so allowed, which is closed by a cast-iron sluice-gate with guide-framing and lifting gear. It is now many years since any water was drained naturally through this culvert; all has had to be pumped. The engine is a 40-nominal h.p. semi-portable compound condensing engine, direct-coupled to a horizontal shaft driving through bevel gearing a vertical spindle centrifugal pump with drowned fan, the fan and spindle being suspended by an adjustable suspension bearing carried on cross girders at the top; the bottom and intermediate bearings are lined with lignum vitæ, and the vertical shaft is cased at these parts with 
gun-metal. The pump was designed to deliver 3,300 cubic feet per minute at $6 \frac{1}{4}$ feet head. This Fen has, however, sunk so rapidly that, in recent years, this plant has been unable to drain the Fen properly, the water not being able to get to the pump quickly enough. It is calculated that the Fen has sunk 5 to 6 feet within the last 50 years.

Owing to the interests of the owners of the banks along Sam's Cut and to the fact that there is a sand-hill (which does not sink), commencing about 1 mile from Hunt's Sluice Pump and continuing for approximately $\frac{1}{4}$ mile, it was considered inexpedient to attempt the deepening of Sam's Cut, having regard to the great expense which the piling or other means of support to the banks would entail. It was therefore decided to erect a new pumping station at the junction of the two main drains where they discharge into Sam's Cut, and to raise the water in Sam's Cut to its old level, so as to obtain the original natural drainage from this point which formerly existed. Instructions were given in October 1912 for the preparation of drawings and specifications for a new pumping installation, consisting of a crude-oil engine and centrifugal pump. Two of the tenders were selected for consideration, and it was decided by the Board to place the contract with the Campbell Gas Engine Co., of Halifax. The foundations and building were carried out departmentally, under the supervision of the Board's consulting engineer, a foreman being engaged to take charge of the workmen; on 11th November the driving of the dams was commenced and the foundations were completed ready for the erection of the engine by 31st December 1912; owing to an unfortunate delay in obtaining the shingle and sand, the completion of the suction and delivery culverts and the commencement of the foundations of the building was retarded. The bulk of the shingle and sand was brought 19 miles by water and then hauled by steam tractor and carts 3 miles to the site of the works, 600 cubic yards of materials being placed in the foundations. The substratum on which the foundations were founded was of a ard sandy clay, the area of the concrete foundations being large so as to avoid any possibility of uneven settlement. Fig. 28, 
Plate 22, shows a condition of things which might occur were this work not properly designed and executed, though a more uneven settlement is usual in the Fens than that depicted.

Fig. 25, Plate 21, shows the general arrangement of the plant, and consists of a Campbell high-compression twin-cylinder oilengine coupled to a 30 -inch "Invincible" centrifugal pump, by Messrs. Gwynnes, London, who were the sub-contractors for this portion of the plant. A $4 \frac{1}{2}$-b.h.p. benzine engine is installed to work an air-compressor for starting, and this same engine drives, by means of a belt on fast-and-loose pulleys, a twin-cylinder singleacting plunger air-pump for charging the pump.

The engine is designed to give 90 b.h.p. at a speed of 210 revolutions per minute, the cylinders being $12 \frac{1}{2}$ inches in diameter by 22 inches stroke. The engine generally follows the usual lines of up-to-date internal-combustion engine practice.

The fuel-oil pump is arranged to work entirely without any packing, the plunger being a ground fit in the lapped pump-barrel, and is capable of very fine adjustment by means of the two locknuts on the end of the barrel. The suction and delivery valves are of a simple and reliable type, being plain balls controlled by springs; all joints are made with metal-to-metal connections.

The atomizer is constructed so that the oil-fuel enters the vaporizer in the form of fine spray, and is adjustable to suit the class of oil used. The fuel oil is stored in a tank outside of the building, from which it is led by a pipe to a small semirotary pump fixed to the engine-house wall, and by this means the fuel-oil service tanks are kept supplied. A small heater is provided, through which part of the exhaust-gases are by-passed, to heat thick heavy oils; and the necessary three-way cocks are fitted so that refined or fuel oil may be used as desired. Watercooling circulation is obtained by means of a 2-inch centrifugal pump, belt-driven from a pulley on the end of the crankshaft, the water being taken from the delivery side of the pumping-station and delivered into a tank, 6 feet by 4 feet by 4 feet, placed outside the building 10 feet above floor-level. This tank provides for an ample supply of cooling water at starting, and a constant 
flow of cold water when running. The oil used is "Resoleum," having a specific gravity of 0.890 at $60^{\circ} \mathrm{F}$, a flash-point of not less than $200^{\circ} \mathrm{F}$. by the Abel close test, and a calorific value of 18,000 B.Th.U. The consumption of oil is $0.481 \mathrm{lb}$. per b.h.p. per hour under full load, but even with this economical consumption the present price of fuel oil, which at this engine-house is 1368 . per ton, does not permit the cost of running a crude-oil engine to compare favourably with the cost of a steam-plant. Oil-engines have however several advantages for small pumping installations in the Fens; they can be started up quickly, run for a few hours only or for long periods, and then immediately shut down.

The boiler feed-water from the Fens is very severe on boilers, as it contains a large amount of mud in suspension and unknown chemical constituents, which come from the large quantity of artificial manures now used on the land. In out-of-the-way stations, such as this one, a saving is effected in the cost of carting oil as compared with coal, the nearest railway station being in this instance 7 miles distant and water transport not being possible as in the majority of Fen pumping stations.

The pump, Fig. 29, stands on its own base, and is directcoupled to the crankshaft of the engine by a Zodel-Voith flexible coupling. It is designed to run at constant speed, and to deliver 22,400 gallons, or 100 tons, of water per minute at a maximum head of 8 feet manometric. The maximum power absorbed is 89 b.h.p. and the guaranteed efficiency 66 per cent.; as the bead decreases, so the volume of water delivered increases, the power absorbed remaining the same.

Several features of the design are of interest, a single impeller of the shrouded-vane type being used; the water enters both sides of the impeller simultaneously, so that there is no resultant endthrust on the shaft and no thrust-bearing of any kind required. An adjustable collar is provided on the tail-bearing, in order to maintain true alignment of the impeller with the casing.

The volute is entirely external to the disk, and is so designed as to obtain the maximum possible conversion of velocity energy into pressure head. The casing is fitted with a side cover, arranged so 
FIG. 29.-30-inch Centrifugal Pump. (Gwynnes.)

Methwold and Feltwell Drainage Board.

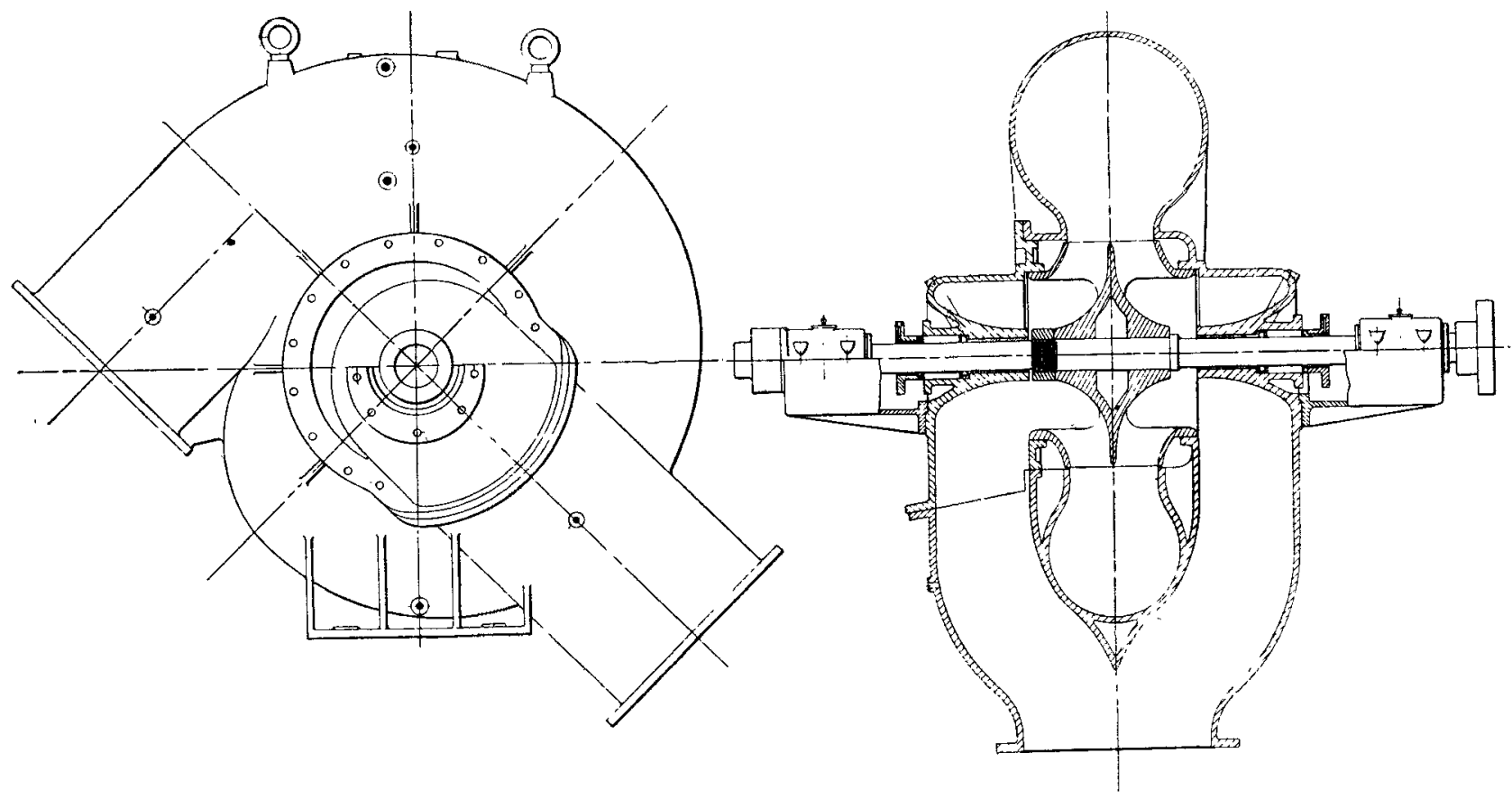


that the interior of the pump may be quickly opened up for inspection or removal of the impeller, without breaking any pipejoints. Hand-holes and inspection covers are also provided for the purpose of cleaning the impeller without opening the casing. Ring-oiling bearing pedestals are mounted on either side of the casing; as these are entirely external to the pump, they are therefore free from any liability to wear, owing to grit which is always present in Fen drainage water.

FiG. 30.-Characteristic Curves 30-inch Centrifugal Pump. (Gwynnes.) Methwold and Feltwell Drainage Board.

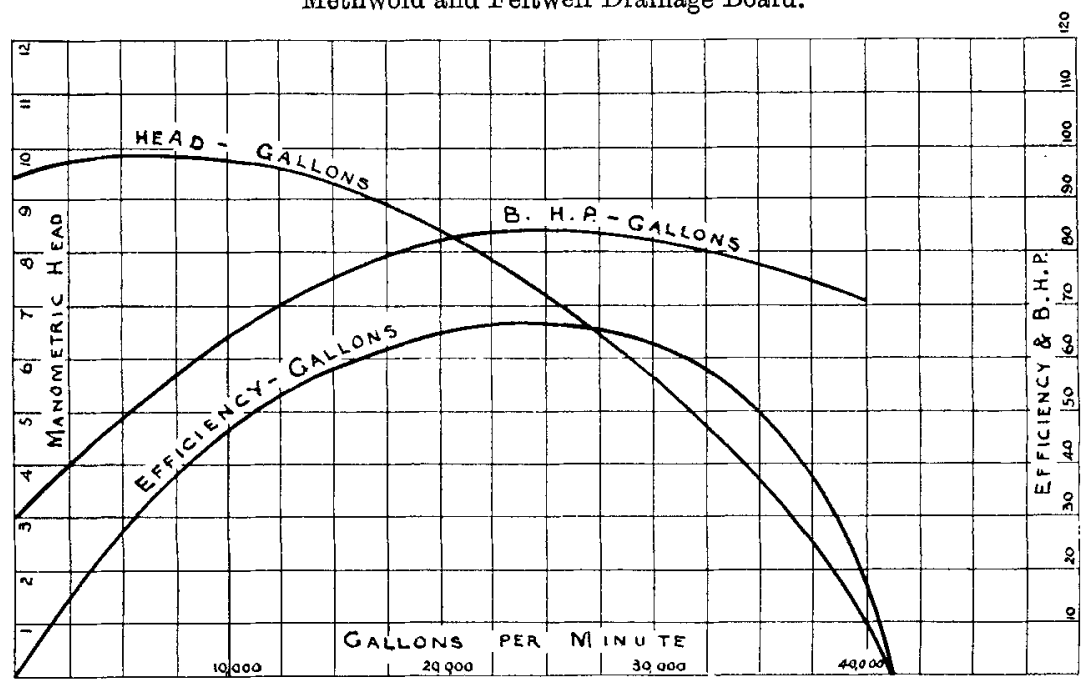

The most noteworthy feature in the design is the perfect selfregulation obtained without the use of any constricted passages or drum rotor. The effect of this self-regulation is that, whatever the variation of head against which the pump has to deliver, the engine is not overloaded, and this is of the utmost importance for pumps driven by oil-engines as they are unsuitable for working against continuous overloads. As the head varies, the quantity of water pumped is automatically regulated so as to keep the power absorbed constant - the speed being also kept constant. This is obtained without any sacrifice in efficiency. The passages of 
the pump being clear and open offer no obstruction to weeds, sticks, etc., which are always present in fen drains. Looking at the characteristic curve, Fig. 30, it will be seen that the horsepower line becomes practically horizontal, and actually drops slightly when the static head drops to zero.

The arrangement of the suction and delivery pipes is, as far as is known, different from any other pumping plant in the Fens, full advantage being taken of the siphonic action obtainable. The stuffing-boxes are sealed by water under pressure to prevent airleakage, and the suction passages of the pump are of special design. So efficient is the pump in this respect that when, owing to the water in the suction channel falling very low, air is sucked in at the suction bell-mouth, the pump will again take the water without recharging after an appreciable interval of time. The enginehouse has been erected as cheaply as possible, consistent with the securing of a substantial building. Several innovations have been introduced to the district in this building, the principal ones being the use of "Eternit" slates for the roofing, the making of the window sills, door lintel and gable copings in concrete, the constructing of the slab supporting the water-tank, also the roadway over the suction channel in reinforced concrete.

This plant started running on the 24th March 1913, so it has not yet had the test of a winter's work. It has however, up to the present, had a considerable amount of work to do, and at the beginning of May ran for 5 days and nights continuously without any trouble whatever. The installation of this new pumping plant will considerably increase the value of the land in this Methwold Fen, and celery and potato crops will now be grown where formerly rough pasture only existed. Other fens could similarly be increased in value and in productiveness, if the authorities controlling them were only progressive enough to install up-to-date pumping machinery and to take up the subject of Fen drainage on business lines.

The Paper is illustrated by Plates 17 to 23 and 9 Figs. in the letterpress.

[The Discussion on this Paper was combined with that on the Paper by Mr. Grantham and Mr. Allen, and commences on page 830.] 


\section{Discussion.}

The Presidenct said that, as the Members were aware, there were three Papers on the programme, all of which were complementary to the other, dealing with the Drainage of the Fens. $\mathrm{H}_{\theta}$ proposed first of all to take the Paper by Mr. Richard Grantham. Unfortunately, the author was unable to be present, and in his absence the Secretary would read an abstract of the Paper. It seemed to be necessary to take that Paper first, because it was rather on general lines. Following that, he would ask Mr. Richard W. Allen to read his Paper on "Modern Pumping Machinery for Drainage of the Fens," and after that, what he might call a sectional Paper would be read by Mr. E. G. Crocker dealing with the "Drainage of the River Ouse Basin," which was a part of the Fens.

The President thought the Institution was to be congratulated on the submission of three Papers, each one of which would be a valuable addition to the Proceedings. Before asking the Members to pass a hearty vote of thanks to the authors, there were one or two points to which he desired to call attention. There was one set of points which was referred to in all the Papers, namely, the apparent difficulty of control, from want of cohesion between the different bodies which had to administer the whole area. Whether it would ultimately be possible to have a Drainage Board which could absorb all the districts or not, he did not know, but divided control must necessarily, he thought, be expensive, because the go-ahead district might be restricted from giving full effect to its plans by the backwardness or niggardliness of its neighbour. From that point of view, it appeared to him some advantage would be gained by all the districts which were concerned getting together, in order that they might formulate comprehensive plans which would be economical for themselves and for their neighbours, and helpful throughout. 
All of the Papers contained reference to old machinery, and it really was wonderful when one came to think of it how those old machines still continued to compare moderately favourably with the more modern apparatus. He remembered a good many years ago going down to the district, and meeting a gentleman who was very anxious to make a bet with him. Of course, personally, he did not like betting, but the gentleman in question was very anxious to bet him that he could stop one of the old beam engines, and that he (the President) would not be able to start it. Having an idea that the gentleman in question wanted to bet on a certainty, he asked what was the point of the joke. The answer was that the beam-engine worked with a $5 \mathrm{lb}$. pressure, and it was perfectly clear that if the engine was stopped, the heat in the cylinder prevented any expansion, and therefore it was impossible to start it again until it got cool. Nevertheless that old pump was working economically for the purpose for which it was put down.

Mr. Grantham referred to a vertical-spindle centrifugal pump worked through gearing (page 781). There might be reasons for the gearing, but for general purposes he did not see any necessity for departing from a direct action. Pumps of that type had, he knew, worked very satisfactorily in a good many places where the lift was comparatively small, and for places like the Fens it was distinctly advantageous that no time should be lost in charging the centrifugal, because the vertical-spindle pump was always drowned and ready to start.

Another problem which must no doubt affect the desiderata, or at any rate some of them enumerated by $\mathrm{Mr}$. Allen, was the sinking of the land and the silting of the stream which made gravitation drainage practically impossible, and, moreover, threw out of use the plant which had been put down with the idea that the lift was going to remain the same. Whatever was going to be done in the future, the desiderata mentioned by $\mathrm{Mr}$. Allen, of which the main one was, quite properly, economy, must be even more considered where the work was subject to the frequent trouble of land subsidence than in more straightforward work. In conclusion, he asked the Members 
(The President.)

to accord to the three authors their very hearty appreciation of the Papers which had been read.

The resolution of thanks was carried with acclamation.

Mr. Herbert A. Humphrey said that Mr. Allen had given to the Institution a most valuable account of the pumping machinery in actual use for drainage of the Fens, and had stated on page 791 that "from experience gained, the machinery most suitable is that consisting of Lancashire boilers, vertical double-acting enclosed forced-lubrication engines running at a moderate speed driving direct centrifugal pumps with horizontal spindles." That type of plant had undoubtedly proved its value for use in the Fen district, but experience was always being extended in this age of progress, and the most modern machinery of to-day might soon become outof-date in the future as more economical types of plant were developed.

In reading through the list of the main points to be considered in the design and construction of drainage machinery for the Fen district, as enumerated by Mr. Allen on page 790, one found the conditions applied with special force to Humphrey internalcombustion pumps. For example, the initial cost had to be kept low; the plant had to be designed so as to run continuously; simplicity of plant was essential; and cost of maintenance and renewals must be reduced to a minimum. Experience had shown that the Humphrey pump with no moving piston, flywheel, shafts, bearings or gearing, most eminently met those conditions; but in addition it had the important advantage of being a long way more economical in fuel consumption than any type of plant described by the author.

Again, where water contained a large percentage of mud in suspension, and was, therefore, very bad both for boilers and condensing purposes, it was surely desirable to eliminate boilers and condensers as far as possible; and in the case of Humphrey pumps, using producer-gas, the only boiler required was very small indeed, just to supply the steam for the producer-blast. If a suction plant was used, no boiler was required. Point No. 8 (page 790) stated " that 
all calculations must be based upon amount of coal consumed to the water horse-power discharged," and in that connection some interesting figures were to be found in the Paper. At Prickwillow there was a 300 i.h.p. steam-engine driving a centrifugal pump which was capable of delivering 150 tons of water per minute upon a 16-foot lift. That was equivalent to 163 w.h.p. Apparently the combined efficiency was, therefore, $54 \cdot 3$ per cent. The coal used was stated to be $3 \frac{1}{2}$ tons for 12 hours' pumping. Supposing that the pump was working at full output all the time, that was equivalent to $4 \mathrm{lb}$. of coal per w.h.p.-hour; but if, as was more likely, the output was about two-thirds of the full load, that wonld imply a coal consumption of $6 \mathrm{lb}$. per w.h.p.-hour. At Wisbech 100 tons of water per minute lifted 15 feet was equivalent to $101 \cdot 8$ w.h.p., and there was a $200-h . p$, engine to drive the pump. If the whole of that horse-power was needed, it would mean that the combined efficiency was 50.9 per cent. There were no actual figures given for that plant. At Soham Mere the information was a little fuller. The pump was capable of delivering 35 tons of water per minute against a total lift of 17 feet, which was equivalent to 40.4 w.h.p. The coal consumption was given as $2 \frac{1}{2}$ to 3 tons of coal per 24 hours. Taking the mean figure, that equalled $256 \mathrm{lb}$. of coal per hour, or $6.3 \mathrm{lb}$. of coal per w.h.p.-hour.

Turning to page 798 of Mr. Allen's Paper, it would be found at Littleport, the plant consisted of two double-acting open compound condensing engines driving direct centrifugal pumps, the steampressure being $120 \mathrm{lb}$. per square inch. Therefore, they had there a first-class modern pumping installation, and indeed, since the capacity of the pump-namely, 150 tons per minute with a 15 -foot lift-was equal to 152.7 w.h.p., they had apparently a pump efficiency of $76 \cdot 3$ per cent., which was extremely good. Exact figures for that plant were given for the year 1913, and it was stated that 600 tons of coal were used during 1,458 hours, also that the total average lift was 11 feet 8 inches, and the total water discharged approximately 175 tons per minute. That gave 138.6 as the average w.h.-p., and the actual consumption being at the rate of $921 \cdot 7 \mathrm{lb}$. per hour, the coal consumed was 
(Mr. Herbert A. Humphrey.)

6.65 lb. per w.h.p.-hour. On the basis of the foregoing figures, it did not seem unfair to assume a round figure of $6 \mathrm{lb}$. of coal per w.h.p.hour as an average of the modern steam-pumping machinery in the Fen district.

With regard to what had been done with Humphrey pumps, be might mention as justification for bringing forward that matter, that the various Commissioners of the Fen district had recently taken the greatest interest in Humphrey pumps, and a considerable number of gentlemen interested in the drainage of the Fens had visited the large pumping station at Chingford where special demonstrations had been held for their benefit. At the Chingford station the official fuel consumption trials had been completed with most satisfactory results, and the average results obtained for all the five large pumps, working at a rate so that their added capacity was $214,000,000$ gallons per day, had shown that they only required $0.904 \mathrm{lb}$. of anthracite gasified in the producers per actual w.h.p.hour. That was easily a world's record in fuel economy under the conditions of quantity and lift. Each pump was tested separately in the presence of the officials of the Water Board and the officials of the Pump and Power Company, and the steam for the producers was raised in a boiler large enough to supply the producers for all five pumps. Consequently, the fuel for steam-which by the way was coke and not anthracite-was 15 per cent. of the fuel gasified, and under normal conditions it would be about 10 per cent. Adding those fuels together, a total consumption was obtained for gas-producers and boilers under normal conditions of $1 \mathrm{lb}$. of coal. In other words, the Humphrey pumps were doing about six times the work of the existing Fen pumps for the same weight of fuel. On account of the higher lift of the Chingford pumps (about 30 feet) it was not quite fair to make that direct comparison, and further, some allowance must be made for the fact that in Mr. Allen's figures he included the coal for raising steam in the boilers. Stand-by losses were, however, much smaller with gas-produoers than with steam-boilers, which was again to the advantage of the Humphrey pump. If a further 10 per cent. were added for stand-by losses, it made a total fuel consumption of $1 \cdot 1 \mathrm{lb}$. of coal 
for the Humphrey pump, but that figure could not be guaranteed under the lower lift conditions which existed in the Fens. A careful consideration of the conditions had led him to believe that the coal consumption, which could be guaranteed for the average conditions which existed in the Fens when using Humphrey pumps, would be 1.6 lb. per actual w.h.p.-hour, and even when using bituminous coal, so as to avoid the expense of anthracite coal, the Humphrey pumps would only consume at the outside one-third of the coal now used to do the same work, and that was a matter of enormous importance to the Commissioners and the ratepayers.

Lastly, it might be asked whether the Humphrey pumps would work satisfactorily on the low lifts in the Fen district, and in reply he would state that the most important inquiry with which his company was now dealing was one where the quantity of water to be raised was over 1,500,000,000 gallons per day, with a lift of 19 feet, and in that case they had been able to guarantee a coal consumption of only $1.3 \mathrm{lb}$. of bituminous coal per w.h.p. Some large Humphrey pumps were being built for use in Italy with a lift of only 3 metres, which was less than that required in the Fen district, and if necessary he was prepared to design pumps of that class to meet the following conditions: Pump to run at normal full load, as measured by horse-power, with variable lift, and that variation might be entirely on the suction side if desired. The efficiency should not vary with the lift more than the efficiency of a centrifugal pump, as for example, as set out in the curve of Fig. 30 (page 828) of Mr. Crocker's Paper.

In conclusion, he would point out that where machinery had to lie idle for a considerable portion of the year, and must be started up quickly, a gas-producer plant with Humpbrey pumps was much more suitable than any steam-plant, because there was no machinery in the ordinary sense of the word to be kept in order, and because a gas-producer and gas-pump could be started more quickly than steam-boilers and a steam-pump. It might be remembered that at Chingford, with gas ready in the holder, one man was able to start three large $40,000,000$-gallon pumps to full load in less than two minutes. Under all the circumstances stated, it was surely 
(Mr. Herbert A. Humphrey.)

reasonable to conclude that, however justified the Commissioners might be in adopting a conservative attitude, yet the Humphrey pump was likely to play an important part in future drainage of the Fens.

Mr. Archibald Carmichate asked whether the figures given by Mr. Grantham in the Table (page 780) regarding the cost of the drainage of the Fens were test figures, or what might be expected to be obtained on the site of plants as installed in the Fen districts. His father had occasion a few years ago to prepare, from the log books of the records of pumping stations as mentioned in the Paper, particulars of the running costs of various types of machinery, and he found on comparing the author's Table with those then obtained that, so far as the steam-plants went, the figures were practically the same, but in the case of the oil-engines (no Diesel engines being at that time installed in the Fens) the author's figures were certainly much lower than were obtained at that date; and the latter figure was confirmed by $\mathrm{Mr}$. Crocker in his Paper regarding the Campbell oil-engine. It must be borne in mind, however, that the Drainage Commissioners did not go into the question of b.h.p. or efficiency; all they had in their mind was that a certain number of acres had to be drained and what would it cost. They wanted to know how many men, how much fuel, how much lubricating oil, and so on, would be required; the question of cost per b.h.p. did not trouble them at all.

At the time to which he was referring, the largest internalcombustion engine installed was a 40-b.h.p. engine, the cost of which worked out per w.h.p. per hour to roughly $0.8 d$. including everything. Mr. Crocker had confirmed that by saying that for a 100-b.h.p. oil-engine the cost was from $0 \cdot 5 d$. to $0 \cdot 6 d$. per w.h.p. per hour. In the case of the steam-engine the average at the date to which he referred was about $0 \cdot 45 d$. to $0 \cdot 5 d$. per w.h.p. per hour.

With reference to the statements made in Mr. Grantham's Paper with regard to the vertical-spindle pump, there was a very typical plant installed at Prickwillow, near Ely, where a verticalspindle pump was working side by side and connected to the same 
drain as one of the horizontal-spindle centrifugal pumps, and he found on comparing the figures which his father obtained, that the efficiency of the horizontal-spindle pump was approximately 10 per cent. better than the efficiency of the vertical-spindle pump. The efficiency of the original scoop-wheel (replaced by horizontal-spindle pump) was about 45 per cent., the vertical-spindle pump about 53 per cent., and the horizontal-spindle pump about 62 per cent. The method of testing adopted in the Fen district was very crude. Everything was done more or less by rule of thumb, and the efficiencies arrived at had to be taken in a very broad sense. Again, Mr. Grantham mentioned that the vertical-spindle pump never lost its water. That would be admitted, of course, provided the water was there, but owing to the subsidence of the land and the deepening of the drains the vertical-spindle pump had been left high and dry. This was actually occurring at this station at Prickwillow, and it was only possible to run the vertical-spindle pump when the water in the drain was at a particular height, and there was very grave danger of the low-lying lands being flooded before the vertical-spindle pumps could be started. The arrangement of the gearing in those days was not what engineers were led to expect in modern plants with gearing of the enclosed type running in oil. The machinery ran in the open with caststeel bevel-wheels. One great point in favour of the centrifugal pump was that it met the existing conditions, and was able to overcome the difficulty of the subsidence of the land by the use of additional lengths of suction-pipes when they were required.

Mr. William H. Alcen (Member of Council) inquired whether the figures that Mr. Humphrey had given were authoritative figures or simply figures that he had taken out himself. Had some separate authority gone into the matter, such as the Metropolitan Water Board, or had the figures been arrived at simply from his own deductions? Secondly, he would like to know how the water was measured. All engineers who dealt with a large body of water knew how dificult it was to obtain accurate measurements. 
Mr. Herbert A. Humphrex, having obtained the permission of the President to reply to Mr. Allen's questions, said that the contract, which was entered into for the supply of the large pumps at Chingford, stipulated that an official trial should be made, and the figures he had given were the results of that official trial. The trial was carried out by three representatives appointed by the Metropolitan Water Board-three absolutely competent and expert gentlemen-and the figures were carefully checked in every particular by three members of his own company. The results were kept quite independently, and they agreed so perfectly that not one solitary question had arisen as to the accuracy of the figures.

The second question asked by Mr. Allen was how the water was measured. A good deal of consideration was given to that question. If there had been plenty of time available, a Venturi meter would have been used, but that would have occasioned a great deal of delay, and would also have been very expensive. His own proposal was to use a submerged weir, the difficulties in the way of using an ordinary weir being considerable, and too complicated to explain at the moment. But eventually the following arrangement was arrived at, based largely on the fact that Mr. W. B. Bryan, the chief engineer of the Metropolitan Water Board, thought from his very large experience that it gave a reliable method of measuring the water. A long rectangular intake basin lined with concrete and stone was used, which was a permanent part of the work having a section easily determined exactly. A certain distance down the basin on the intake side was measured; floats were placed at even distances across the stream and timed over the measured distance. Each float consisted of an ordinary copper ball float, then a piece of chain and then another ball float. The hollow floats were loaded with water until the top float just practically disappeared below the surface. Consequently there was one ball float just disappearing on the top, and there was another float almost touching the bottom of the channel. A number of these double floats were used, and the average time was taken for calculating the mean velocity. It was evident that the top ball of each float tried to go just a little faster than the mean velocity of 
the stream and that the bottom ball tried to drag behind, but as they were fastened by a chain the two thus connected gave a very fair average velocity of flow at the particular part of the stream. There being a number of such floats at points across the section, measurements were obtained within quite small limits of error. That was the method adopted, and in talking it over with civil engineers accustomed to water measurements, he was told that, if anything, it was against the pumps rather than in their favour.

It was worthy of note that the total cost of the Humphrey pumps at Chingford, including all buildings and foundations and gas-producers, was considerably less than the corresponding total cost for a steam-driven centrifugal pumping plant.

Mr. Mrchaed, Longridge (Vice-President) desired to ask those who had had experience of the Fen drainage work a question which might to them perhaps be a foolish one. Many years ago great difliculty was encountered in obtaining stable foundations for the piers of a bridge on the Calcutta and South Eastern Railway in India. The bridge had to be built upon quicksand, and after many attempts the engineer finally hit upon the plan of floating the piers of the bridge upon large platforms of concrete. He desired to ask the Fen engineers whether it would not be possible, especially as reinforced concrete was now available, to float engine-houses upon similar platforms so that they would subside with the land, in which case, instead of having to alter or make new foundations, all that would have to be done would be to lengthen the discharge-pipes of the pumps.

Mr. Edwand B. Ellingron (Past-President) said he appreciated the Pápers very much, and thought they would enrich the Proceedings of the Institution. He was glad to hear the remarks of Mr. Carmichael, and he thought it would add to the value of all three Papers if the authors would give detailed information as to the cost of running the very old and historical plants described in the Papers. The most complete statement was that given by Mr. Grantham, but it was evident, from what Mr. Carmichael had 
(Mr. Edward B. Ellington.)

said, that there was a necessity for further detailed particulars. The efficiency of the scoop-wheel, for instance, was stated to be generally estimated about 30 per cent. Mr. Carmichael, on the other hand, had stated that when his father took the measurements he arrived at an efficiency of 45 per cent. The further statement was made that the beam-engine of 100 h.p. working the scoopwheel used 30 tons of coal per week, and that the present lowpressure engine cost $0 \cdot 39 d$. per pump h.p. per houx. He would like to know whether that figure referred to the 30 tons of coal per week; he believed it did. But supposing that were so, he really could not believe that since 1830 , when the steam-pressure was about $12 \mathrm{lb}$. per square inch, the $0 \cdot 39 d$. had been reduced only to $0 \cdot 332 d$. with a modern high-pressure condensing steam-engine. That really seemed incredible. The figure for the Diesel oil-engine was stated to be $0 \cdot 119 d$., but that he presumed was a theoretical figure, because there was no Diesel oil-engine at work in the Fen district. If he was wrong the author would correct him, but he believed that was the fact. Theoretical figures were very good as far as they went, but it could not always be taken that they would be realized in practice. As Mr. Carmichael stated, the Fen Commissioners wished to know the total cost and not the cost per b.h.p., but engineers wanted to have the data and accurate figures. It was easy for engineers to make all the necessary allowances when estimating commercial costs, but commercial figures were not those that engineers were most anxious to obtain. So far as Mr. Allen's Paper was concerned, particulars were given from which at any rate the cost of fuel could be obtained for the modern plant, but if the author would add to his Paper comparative figures for the plant displaced, it would be very valuable and interesting information, which would he was sure be appreciated by the Members. The same remarks/applied also to Mr. Crocker's Paper. He would not pursue the subject further, but hoped when the Papers were published in the Proceedings, the particulars would be added.

Mr. A. E. Dovglass thought that Mr. Ellington had referred to the main point connected with the Papers, namely, that they were 
very interesting, but that they dealt with obsolete machinery. Nevertheless, as the authors claimed that the machinery was fairly economical, he presumed, therefore, they would not object if something were said with regard to modern machinery. Pumping engineers always dealt with foot-lb., and if the three Papers had contained a statement of the cost per foot-lb. of water raised, it would have been very much easier for comparisons to be made. Mr. Humphrey had had to make many caleulations in order to try and get some definite figures with which to make comparisons. It would be most interesting to know what was paid for fuel in the Fen districts; in South Staffordshire rough slack cost about 78. to 8s. per ton.

Mr. Allen mentioned on page 798 of his Paper the high efficiency of the centrifugal pump. Personally, he had never yet found a highly efficient centrifugal pump, although the makers claimed high efficiency for them. In South Staffordshire he had in his charge a high-speed Belliss and Morcom compound engine driving a large Mather and Platt centrifugal pump, and the over-all efficiency at the official trial was only about 68 per cent. This could not be compared with the high efficiency obtained by triple-expansion pumping engines working ram pumps. He had just put down a triple-expansion engine, working ram pumps against a fairly heavy head, to replace an old Cornish beam-engine; the beam-engine used 5,000 tons of slack per annum, and the triple-expansion engine 2,000 tons for the same work, which showed very clearly it was perfectly right to scrap obsolete plant and put in modern machinery. In fact, all the engineers in South Staffordshire, whether they were pumping from deep bore-holes or in connection with canal work, were taking out the old plant and putting in modern. At one station a centrifugal pump and two modern compound condensing fly-wheel engines were installed. Although the centrifugal plant was put in at a later date than the fly-wheel engines, he had been obliged to stop the first named and restart the others simply on the score of economy, the saving in fuel being $£ 300$ to $£ 400$ per annum. 
(Mr. A. E. Donglass.)

Mr. Humphrey had very naturally mentioned the Humphrey pump; there was no doubt that the pump was economical, and it would perhaps be very useful in the Fen district, but he was afraid it would be useless for pumping from deep bore-holes or wells such as existed in South Staffordshire, where the pumps were down 300 feet.

The Papers were very interesting and instructive so far as they went; they gave an accurate description of the plant installed, but, as a pumping engineer, he could not help thinking, considering the financial aspect of the question, that the whole of the plant ought to have been scrapped years ago, and central modern pumping stations put down; perhaps Mr. Humphrey would be able to accommodate those in authority in that respect.

Mr. Charles Hawksher (Member of Council) thought it was of importance in all cases where comparative figures were given that not only should the cost per 1,000 gallons or ton, or whatever the measure might be, be stated, but that the kind of fuel employed should be named, and the cost of the fuel at the place of user, otherwise it was impossible to make correct comparisons. In comparing the old types of machinery with new types, it should always be borne in mind that the figures for the old type had probably been ascertained when it was at its worst, because having in view its probable replacement, the old type of pumping apparatus was not likely to have been kept up in regard to efficiency.

The settlement of the land referred to, so far as it occurred above the water-line, might readily be accounted for by the removal of the water from the peat by the draining operations, but the settlement below the water-line could not be due to that cause, though it might be consequent on the increased weight of the peat above the water-line, owing to its being no longer immersed in water. It would be interesting to know the amount of the subsidence below the water-line.

In reference to the measurement of large quantities of water, this was sometimes effected by allowing the water to flow through a number of circular apertures in a metal plate, the apertures 
being all of exactly the same diameter and under the same head of water. The water flowing through one aperture could be measured by a meter, and, on the quantity passing through the meter being multiplied by the whole number of apertures, the total quantity of water could be ascertained.

Mr. Richard W. Allen, in reply, said the President in the remarks he made in opening the discussion referred to the question of divided control. Personally, he had not very much experience of the working of the various bodies in the Fen district, but he knew that a difficulty had arisen in connection with the question in the county of Bedford. Meetings and inquiries had been held for many years past for considering the question of the deepening and widening of the River Ouse; other counties had been invited to join in the discussions, but the apathy shown in the direction to which he referred was extraordinary. He supposed that all people were human in that respect, that is, the people living in the uplands thought very little about those living in the lowlands, and if a suggestion were made to put a tax upon those living on the higher ground to pay for drainage works connected with those living on the lower lands, they would not see eye to eye with them about it. In counties like Bedfordshire, difficulties had been experienced in getting the various bodies together to discuss the question. The President had referred to the pleasant trip which was arranged to be made on one of the following days up the River Cam. He suggested to the President that should he visit one of the modern pumping stations described in the Paper, and if he cared to make a bet that he would be able to start one of the new pumping engines, he (Mr. Allen) ventured to state that the President would win (page 831).

The Members had received a most interesting lecture from Mr. Humphrey on the excellence of his pump; they had heard all of its advantages, but nothing had been said of any of the disadvantages. As mechanical engineers he was sure the members would agree with him that, while there may be advantages in this new type of pumping machinery, there were certainly some disadvantages, but 
(Mr. Richard W. Allen.)

he supposed that Mr. Humphrey was not prepared to state what they were at the Meeting. Nevertheless, Mr. Humphrey's remarks were extremely interesting, and he thought everyone must be gratified to learn that the conditions mentioned in the Paper could be fulfilled by the Humphrey pump. It must be borne in mind, however, that the Paper described the existing machinery and not machinery which was likely to be erected in the future, but at the same time it was advisable to bear in mind that the Humphrey pump might be a competitor to the old and well-tried servant, the centrifugal pump. Mr. Humphrey had made some comparisons with regard to the respective fuel consumptions. The figures given in the Paper were those received by the Commissioners of the various districts; they were facts which could not be disputed. It was not always the case, however, that the machinery worked under the conditions of the duties for which it was designed and as described in the Paper. For instance, the rivers rose very considerably at different times; the head against which the pumps worked was therefore very much increased and the quantity of water discharged also. The weight of coal stated was as measured into each pumping station. Not only the question of raising the steam in the boilers had to be kept in mind, but also the very important point which he did not think Mr. Humphrey quite realized, that the pumps had to remain idle for a considerable period, and the coal consumption given in the Paper included the banking of the boilers, the steam required for the feed-pumps and other auxiliary machinery, as well as supplying the engine driver and boiler man with fuel for domestic requirements.

Mr. Humphrey had also referred (page 833) to the coal consumption and efficiency of the latest machinery which was installed in the year 1912, but he wished to remind Mr. Humphrey that the quantity of coal burnt, 600 tons, was very largely in excess over the normal quantity due to the lengthy trials which were made at the time, and to the fact that the boilers and the steam-pipes were not lagged. The pumping machinery was erected in a very great hurry and set to work in the shortest possible time, on account of tremendous storms which took place over that part of the country 
during the month of August 1912. Although there was no doubt that the quantity of coal referred to was burnt, it was not a test in the proper sense of the term. He assumed that the figures with which Mr. Humphrey had compared the 600 tons related to a test of the Humphrey pump suitably tuned up for this special test, which was hardly quite a fair comparison. He hoped $\mathrm{Mr}$. Humphrey would take those words in the spirit in which they were said.

He understood Mr. Michael Longridge to ask (page 839) whether the isolated pumping machinery could be erected on a floating set of foundations. This arrangement might be carried out, but he thought it would be extremely costly. With the existing horizontal-spindle pump with vertical-suction pipes, when the land subsided, as Mr. Carmichael had mentioned, it was an easy matter to add another length of suction-pipe and get over that difficulty in a very inexpensive manner. This design of suction-pipe lent itself very readily to that peculiar circumstance.

Mr. Ellington had asked (page 840) for further information with regard to the cost of running of the old plant. It was rather difficult to get those costs because, as had been mentioned, in the Fen district the records for coal, oil and waste were not very accurately kept. It was not possible, for instance, to make the same comparisons as could be made in up-to-date central electric light stations. He thought, however, he would be able to obtain further information, and he would be only too pleased to supplement that part of the Paper.

Mr. Douglass, who stated he had had experience in dealing with centrifugal pumps in Staffordshire (page 841), did not appear to be altogether favourable to the centrifugal pump, and was rather struck by the remarks made in the Paper in regard to high efficiency. The term " high efficiency" was used in that particular case in order to convey the difference between the modern designs of high efficiency pumps, and that of the older type. The efficiencies of the centrifugal pump had been improved from year to year; when conditions were suitable, especially for larger quantities, guarantees of 80 per cent. efficiency could be obtained in practice. 
(Mr. Richard W. Allen.)

Lastly, Mr. Hawksley had asked for information in regard to the kind of fuel employed and a comparison of the prices (page 842). He hoped to be able to supplement his Paper with that information. He was very much obliged to the Institution for allowing him the honour of reading his Paper at such an important Meeting.

Mr. E. G. Crocker, in reply, said that although many important points had been raised in the course of the discussion, Mr. Allen had answered nearly all of them. There were, however, one or two questions to which he wished to reply. With regard to the records of costs of the various pumping stations in the Fens, he desired to say it was very difficult to obtain any reliable information on that point. The Commissioners were not prepared to pay for the collection of those records, and unskilled men were in charge of most of the stations, many of them being little better than labourers. So far as the amount of coal consumed was concerned, the coal came into the yard, and that was the only record kept. Out of that coal the engine-driver and foremen had their. houses supplied with coal, and there were various leakages which took place during the summer months in the pumpings of the drains. The same remark applied also to lubricating oil, which was used for various other purposes in the Fens than the actual work connected with the engines, so that it was very difficult to get reliable records.

Mr. Eluinaton presumed that the leakages were constant, so that the comparison was not affected.

Mr. Crocker, continuing, said there was no doubt that much of the present machinery was not as efficient as it might be, and that more modern machinery could be installed which would give greater efficiency. When modern machinery was installed, however, it would be necessary to have more skilled men in charge of it, and far better results and greater economy from the Commissioners point of view would be obtained. 
With reference to Mr. Humphrey's remarks in reference to the Humphrey pump, personally he considered from his experience there was no doubt at the present time it could not equal a centrifugal pump for working in the Fens. Considering the water that had to be dealt with, and the conditions under which the centrifugal pump had to work, although it might not be so efficient as more modern forms of pumps, yet he thought it was the most suitable form of pump at the present time. Mr. Humphrey had referred to the lower initial cost of the Humphrey pump. He had had no personal experience on that point, but he knew of one recent case in which the Pump and Power Co. tendered against the ordinary centrifugal pump and steam-engine, in which he thought he might say without any breach of confidence that the tender of Mr. Humphrey's Company was exactly double that of the tender for the steam-engine and centrifugal pump. It was very hard to reconcile that fact with Mr. Humphrey's statement as to the low initial cost. Another objection which he thought he might put forward was that it was necessary to put down very expensive foundations for a Humphrey pump. Although no doubt many of the Fen Commissioners would be only too pleased to install modern plant, they must necessarily have a guarantee as to the low maintenance and working expenses of such a plant, and in addition they must take into consideration the initial cost. Personally, he did not think the question of initial cost was an important point; it was a survival of olden days, and an agricultural community was very frequently luath to spend money in order to obtain a slight improvement in efficiency. They objected to spending an extra $£ 100$ of capital, which he thought was a very short-sighted policy. Whenever he had been asked to advise, he had stated that it was best to obtain the most up-to-date and efficient plant, being convinced that the people would ultimately reap the benefit of it. 


\section{Communications.}

Mr. G. P. M.AIR wrote that Mr. Grantham in his interesting Paper drew a distinct dividing line between the old Appold pumps and centrifugal pumps; in fact, he treated them as totally different machines for raising water. The Appold pump as made by Messrs. Easton and Amos and the vertical-spindle pump by Messrs. Gwynnes of forty to fifty years ago were the same in principle as the modern vertical-spindle centrifugal pump. At the present day centrifugal pumps were installed with either vertical or horizontal spindles, depending entirely on circumstances ; the two pumps were identical, except for bearings or other details which were necessary owing to the different positions of the shafts. For Fen drainage, horizontalspindle pumps were preferred, as they eliminated any loss of efficiency through gearing and had the further advantage that the foundations were simpler, which was a very important item when the difficult Fen soil had to be dealt with. They were also more accessible, but the vertical-spindle type was used largely in certain cases and high efficiencies were obtained.

Mr. Grantham further stated that there was a serious loss when using horizontal-spindle pumps, owing to the same being placed above the two water surfaces, as the water had to be lifted up and run down again. This, however, was clearly not the case, for the pump and pipes formed a siphon above the water levels, and there was therefore no loss except that due to pipe friction; this amounted to about the same value as the losses due to water entering and leaving the entrance and delivery passages of the vertical-spindle or Appold pumps referred to in Mr. Grantham's Paper.

Mr. Humphrey, in his remarks on Mr. Allen's Paper made the statement that his pumps were capable of doing the same amount of work as present-day Fen pumps, but with one-third of the fuel. There was one point he had overlooked in comparing the Chingford pumps with centrifugal pumps in the Fens, and that was, that the Fen water varied considerably in height. This was a matter easily and efficiently dealt with by centrifugal pumps, but apparently not so by the Humphrey pumps, for a varying head existed at 
Chingford with the reservoir partially full, a condition constantly met with in practice. The Chingford pumps, however, were arranged to raise the water always to the highest level, from whence it ran down an open cascade into the reservoir, a fine spectacular sight no doubt, but it could scarcely be called good hydraulic practice. As in the Fen district the maximum lift was seldom reached, the Humphrey pumps would be working at a great disadvantage. The consumption figure mentioned by Mr. Humphrey for the Chingford pumps would presumably be obtained under the maximum static head, so that if the head were halved, which it would often be, then the consumption per w.h.p. measured on the actual static head would be doubled, whereas in the case of a centrifugal pump the consumption would not be increased by more than 10 per cent. Mr. Humphrey's estimate, therefore, required considerable modification for Fen drainage or for any other duties with a varying head.

Mr. Wrlliam H. Patchell (Member of Council) wrote that the point raised by the President, of central control, was very interesting, but it must not be taken to mean a central pumping station. There was, in the Metropolitan Water Board, an instance of the cost and difficulty in safeguarding conflicting interests and exercising control by a central authority. The Fens could ill bear the cost of such an experiment.

If a central power station could be arranged to operate the scattered pumping-plants, the problem would not be a difficult one, but this would mean that the transmission lines and power station were only in use for pumping operations for a short time in every year. Mr. Allen, for instance, on page 793, mentioned one pump as having operated 209 twelve-hour days in one year, which was nearly 30 per cent. of the possible working hours, but to make up for the stand-by hours it would be necessary to find other outlets for electricity, and its use would have to be developed for agricultural and other purposes in the district. This would necessitate a capital expenditure on plant for the farmers and others, which probably they would not be prepared to face, and would have to be arranged 
(Mr. William H. Patchell.)

for by the Power Station Authority. Scattered pumping plants would be necessary, as a central pumping station would call for an extensive canalization, the cost of which would be prohibitive even if the levels permitted it.

The problem, as disclosed in the Papers, might be divided into "rainfall" and "ground-fall." Mr. Allen (page 802) gave the record of the rainfall in the district since 1901. Records were available which showed that for the thirty-eight years from 1875-1912 the average rainfall had been $23 \cdot 18$ inches. This must be compared with the 31 inches in 1912. Mr. Crocker (page 812) mentioned 25 inches in eight months, and in the adjoining area in August 1912 from 4 inches to $4 \frac{1}{2}$ inches fell in a very few hours over a very large area, while in some parts of that area the rainfall amounted to 8 inches in a few hours. From figures given by Mr. Allen, it appeired that the pumping provision made was from 1 ton to $1 \cdot 2$ ton per hour per acre, or, in round figures, about one hundredth of an inch per hour per acre.

As regards the ground-fall, very little had been said in any of the three Papers about the strata in the Fens, and it was really the underground strata rather than the surface that made this problem so interesting. No reference to the Fen drainage was complete without a reference to S. B..J. Skertehly's "Geology of the Fen Land," published as a Memoir of the Geological Survey in 1877. Mr. Skertchly there gave some sections from which it appeared that single beds of peat occurred 18 feet in depth, and in some places there were two beds of peat 9 feet to 10 feet in thickness separated by a bed of silt about 7 feet in thickness. Water would find its own level, but not quickly, and if pumping operations were started at one place in a big sponge of peat, the effect would be immediately felt in the neighbourhood, and more gradually felt over a very large area.

The record of the iron post in Whittlesea Mere, referred to by Mr. Grantham (page 778), might well be slightly elaborated. This column was put down in 1848 , according to the records in the Journal of the Royal Agricultural Society, Vol. 21, 1860. The ground sank 7 feet 8 inches in the twenty-two years up to 1870 , an 
average of $4 \cdot 18$ inches per annum. In the next five years it only sank 1 inch, an average of 0.2 inch per annum, giving a mean fall of 3.44 inches in the twenty-seven years from 1848 to 1875 . New engines were erected in 1876, when Mr. Grantham recorded the ground had sunk 8 feet. Probably this record was taken after the new engines had been started, hence the 3 inches drop in the one year. The fall from 1875 to 1913 was 2 feet 3 inches or 0.71 inch per annum, and the total fall over the sixty-five years of 10 feet is 1.85 inch per annum. This fall, with modern systems of foundations and motor-driven pumping-plants should be easily and successfully dealt with.

As regards costs, Mr. Grantham (page 780) compared certain methods of operating the pumps. The writer hoped that Mr. Grantham would be able to supplement these figures with particulars as to the b.h.p. of the individual engines referred to, and the cost of the coal or oil delivered at the engines.

Mr. F. Sanderson Robiss (Boston, Lincs.) wrote that a few scoop-wheels were still erected in the Fen districts, but their number was steadily decreasing and either the vertical- or horizontal-spindle types of centrifugal pumps were used. Personally, he favoured the latter set above highest flood level and having submerged outlets, so as to save the constant lift necessary with the former, whatever the difference of the water-level might be.

For small Fens, up to say 4,000 acres, he was in favour of the plant with which the agricultural labourer was best acquainted, that is, either the overhead or underneath type of semi-portable engine coupled up to the pump direct, where the foundations were good, otherwise it should be belt-driven. Where the plant was used infrequently, say two or three months or even less in the year, the writer did not consider that high-pressure boilers in brick settings were advisable, as in the dampness of the Fens the condensation and moisture soon corroded the shell; and in these small plants repairs and overhauling were never thought of until something had gone wrong. This type, as well as internalcombustion engines, was quite suitable where the plant was in 
(Mr. F. Sanderson Robins.)

constant use. He knew one case where a 40-h.p. oil-engine was not used for a year, and then, when wanted in a sudden flood, the piston was rusted up and a new liner had to be put in the cylinder. Of course, ample power must be provided in an oilengine, because in a sudden emergency or with a bad compression, unlike the steam-engine, one could not keep the safety-valve down and so obtain more power. The amount of rainfall to be pumped was usually reckoned as $\frac{1}{4}$ inch in the twenty-four hours, but this amount was dependent on the amount of high land draining into the area and of the soakage through the boundary banks. The writer knew of a district where $\frac{7}{8}$ inch was allowed for.

The capital cost had, as a rule, to be kept as low as possible, so that no great refinements were allowable, and with such little running time there would not be much advantage in extras, to reduce the fuel consumption by compound-condensing engines, economizers, etc. If funds were available, it would always be advisable to put down two sets of plant capable of doing the work of one larger set; a plant that could deal with the maximum flow in one unit was severely handicapped when dealing with a small flood or the later stages of a big one, as the plant had to be constantly stopped and started to deal with a small flow.

Mr. M. HoLroyd SmITH wrote that the Papers on the Drainage of the Fens and of the River Ouse Basin dealt with a subject more within the province of civil than mechanical engineers, and it was, therefore, natural that the discussion should mainly be upon the various types of pumping machinery described. For low lifts, it seemed to the writer that a scoop-wheel properly designed would, for first cost, durability, and efficiency, beat the present type of turbine-pump. He wished now to deal with the larger question already mentioned by the President, namely, the necessity of some authoritative control over the entire area. The troubles, the avoidable troubles, that now obtained resulted largely from divided interests and the short-sighted policy of many masters.

Three years' residence in Huntingdon had given the writer the opportunity of observation, and he was convinced that if 
proper attention were given to keeping the beds of the rivers and backwaters clear and maintaining the bank, then the pumps would have comparatively little to do. Their sole duty should be to deal with the rainfall on the Fens, not with water from the higher lands that in flood time could not find its way to the sea because of silt and weed in the main river and the choked-up condition of the backwaters. For example, he would suggest that an inspection be made from Offord to St. Ives, and it needed no expert engineer to condemn the condition of the water-way. Not only should the main water-way and by-ways be kept clean and free, but in many cases alterations and improvements should be made in the weirs and flood-gates. There should be devised and constructed a semi-automatic regulation of the water-level independent of the caprice of the attendant. He used the word "caprice" as a mild term for expressing his meaning. For example, supposing there had been a few days' rain and the water was rising, the attendant waited until the upper water overflowed the banks and then opened all the gates and went home. The consequence was that in all probability the flood-gates were neglected until the upper stretch of river had run nearly dry. The writer had seen the water at Godmanchester Bridge vary a foot in height within a few hours in fair weather for no excusable reason, only from the caprice of the attendants above and below. This in fair weather was annoying only to boaters and anglers, but in bad weather the results were serious.

Mr. Crocker in his Paper described weed-cutting by means of a somewhat rudimentary apparatus that could be improved. He wished to make a most emphatic protest against the practice of cutting weeds and leaving them to float down the river to accumulate in masses and choke some outlet or by-water. They then rotted and sank, forming an unwholesome mass which fouled the river bed. After a weed-cutting time, the odours from the water were positively objectionable, and people wondered why the fishing was not as it used to be, and why coarse fish tasted muddy, and also why it was unhealthy to live near to a river side. If the weeds when cut were removed from the water, considerable increase in fish life would occur and the health of the people 
(Mr. M. Holroyd Smith.)

would improve. He ventured to think that if properly stacked and treated, the weeds now left as a pollution could be profitably employed as a land dressing.

The writer felt that the water-ways of Fngland were neglected and deserved more attention than they now received, and he hoped that something would be done to place the drainage of the River Ouse Basin under one authoritive control, so that the evils he had mentioned might be remedied.

Mr. Arthur TItrey wrote that during the Meeting he had visited the Harriermere windmill pumping-station (page 788), and was interested to find in existence such a good example of the old country millwright's art. The only iron parts of any size were the wind-shaft and the scoop-wheel shaft which were of cast-iron with squares cast upon them to receive the bosses of the timber gear- and scoopwheels. The wind-shaft was in two parts, united by means of a pair of flanges and bolts, apparently for the purpose of renewing or re-turning the end taking the thrust.

The gear-wheels and the scoop-wheel were of timber with arms framed together so as to form square holes to suit the squares upon the shafts, upon which they were fixed by means of wooden keys or "stakes." The teeth of the gears were simply hard wood pegs turned to two diameters and driven up to the shoulder, and they appeared to be still a good tight fit. No attempt was made to shape the working part of the teeth, which in the course of time wore to approximately the proper shape. The first gear-wheel upon the wind-shaft had crown teeth, and its outer circumference was surrounded by a brake which was normally held on by a weighted lever, the latter being raised when needed by means of a drum-andspindle purchase and a hand rope. The second wheel, on the vertical shaft had also crown teeth. The vertical shaft was of timber with iron gudgeons; at its lower end was a "lantern" or "trundle" pinion whose teeth consisted of turned pegs driven through the shrouds at the side of the pinion. This pinion geared into crown teeth upon the face of the massive 24-foot wheel upon the scoop-wheel shaft. 
The head of the mill was turned to face the wind by means of a timber tail-frame nearly reaching the ground, and having upon it a hand-winch and chain. In the circle swept by this frame round the house were driven posts projecting about six inches or so from the surface of the ground. In the top of these posts were driven heavy iron loops or staples, and the winch-chain being hooked to one of these staples, the head was hauled round in the direction required. These pasts also served to anchor the whiparms when the mill was stopped.

Canvas sails were set upon the whips by climbing to the level of the centre of the wind-shaft and attaching the sail to the crossbars as one descended. Wooden hooks nailed to the whip assisted in the reefing of the sails.

The house was framed in timber and boarded, and was upon a brick base. All the timber used was very massive, and this interesting engineering relic was probably at least 180 years old. It was inhabited up to ten years ago, and the great-great-grandfather of the then occupant also resided in it. The mill stopped work a few years ago when a cut was made to drain the water down-stream to the Prickwillow pumping-station, there to be raised to the river level.

Mr. Allen, in the Paper, referred to the efficiency of scoopwheels as being low. No doubt this was so in the case of many of the older wheels which were very crude machines. Careful tests with well-designed wheels have shown that was not necessarily the case however. Messrs. James Watt and Co. made tests upon a wheel at the Hundred Feet River station in 1882, in

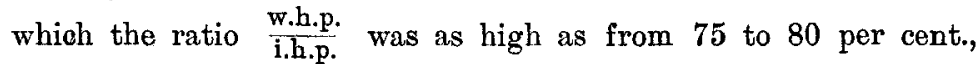
and this was substantially borne out by other tests, results of 67, 68, and 72 per cent., having been obtained in Holland, at Wexford Harbour, and at Adria, in Italy, respectively. These figures were given by $\mathrm{Mr}$. W. H. Wheeler in a series of articles which were published in The Engineer in 1887.

Mr. C. Humpeney Wingrield wrote that he was much interested in the three Papers dealing with the drainage of the 
(Mr. C. Humphrey Wingfield.)

Fens, as he was very familiar, as a boy, with parts of Whittlesea Mere where he used to fish in the dyke* near the engine-house, in which he remembered seeing the first centrifugal pump referred to on page 781 of Mr. Grantham's Paper. Its spindle was horizontal, not vertical, as might be supposed from the description. It was driven by a beam-engine of 25 n.h.p. through gearing, and it worked from 1852 until superseded in 1877 by a vertical-spindle pump of greater capacity. In those days the Fens were just becoming fit for cultivation, and experiments were made by a few farmers to find what would grow in the damp peaty soil. He well remembered that " cole rabbi" proved itself more suitable than any other root crop. It was strange now to see from the Great Northern Railway between Huntingdon and Peterborough large tracts of Fen-land under cultivation and dotted with trees and spinneys.

He believed the scoop-wheel, if properly designed, was likely to be at least as economical a machine for low lifts as the centrifugal pump, but those shown in Fig. 1 (page 788) by Mr. Allen and Fig. 27 (page 822) by Mr. Crocker were not designed in the best manner for efficiency. The proper construction for this purpose was thoroughly explained by Mr. W. Airy in Engineering (Vol. IX, pages 183, 194, 230, 274, and 321). A Dutch form of scoop-wheel with paddles of somewhat similar shape to Mr. Airy's design was illustrated on page 174 of Vol. VIII of the same journal, but the important feature of Mr. Airy's sliding apron, which prevented the paddles beating the dead water, did not form part of this design. Some mention had been made of steam-turbines but the fact that machinery in the Fens, like that used on farms, was in charge of men with the minimum of mechanical training, made it imperative that it should be free from delicate parts, not readily got out of order and easy to repair; conditions which put steamturbines out of court.

An interesting Paper on Pumping Machinery in the Fenland and by the Trentside would be found in the Proceedings of the Institution of Civil Engineers, $\dagger$ and Mr. W. Wells, who had a

* In Norfolk-dyke is a wall; in the Fens it is (or was) a wide ditch.

† Proceedings, Inst. C.E., 1887-8, vol. xciv, page 277. 
great deal to do with the drainage of Whittlesea Mere had contributed a Paper on the subject in 1860 to Vol. XXI of the Journal of the Boyal Agricultural Society of England.

Mr. Richard F. Granteam, in his reply to the remarks made in the discussion on his Paper, wrote that the figures referred to by Mr. Carmichael (page 836) represented a comparison of the actual cost of working the various engines and pumps. In the case of the Diesel oil-engine, he was not aware that such an engine had been employed in the Fens; the figure given was not theoretical as Mr. Ellington remarked (page 840), but was the result of the working of a pumping-engine for waterworks. Its adoption, however, would of course depend on the price of oil, as the first cost of the engine was higher than that of steam-, gas-, or oil-engines. In the particular case at Prickwillow, no doubt Mr. Carmichael was correct in saying that the efficiency of the scoop-wheel was 45 per cent., but this percentage would not apply generally to scoop-wheels. It would as a rule be found to be nearer 30 per cent. than 45 per cent.

The Appold pump would not, of course, work when there was no water in the drain, but the settlement of land in the Fens was well known, and could be guarded against by putting the pump down to a sufficiently low level. Foundations for it, to which Mr. Mair referred (page 848), were sometimes a difficulty, and perhaps would be the factor in determining what kind of pump to adopt. But he (Mr. Grantham) had seen many of these pumps which had been working for many years, in which neither the difficulty caused by settlement of the land nor that by foundations had occurred.

The figure of the cost of working the beam engine of 100 b.h.p., alluded to by $\mathrm{Mr}$. Ellington (page 840), was the 30 tons of coal per week.

The author did not state, as Mr. Mair remarked, that there was a serious loss when using horizontal-spindle pumps, nor did he intend to convey that impression. What he desired to point out was that the Appold pump had the advantage of lifting the $3 \times 2$ 
(Mr. Kichard F. Grantham.)

water from the low-level direct to the high-level without lifting it up through pipes to a fixed level. Mr. Mair admitted an advantage in the Appold pump when he referred to pipe friction in the horizontal-spindle pump. Nor did the author desire to treat the pumps as different machines. They were not; the difference lay in the method of fixing and working them.

Drainage Commissioners, of course, only wished to know how much coal or oil would be used and what the working expenses of engines would be, but engineers employed by them must study the details of the quantity of water to be lifted, the height of the lift and the power required.

In reply to Mr. Charles Hawksley's remarks (page 842) as to the settlement of the land in the Fens, it was no doubt due to the abstraction of water from the land by drainage operations and by evaporation, but he (Mr. Grantham) was not aware that there was any settlement in the bottom of the drains nor any subsidence below the water line. Hence the difficulty in very flat land in keeping the water level sufficiently below the surface of the land increased as time went on.

Mr. Richard W. Alien wrote, with further reference to the information asked for by Mr. Ellington (page 840) regarding the cost of fuel and the comparative running cost of the various types of plants installed in the Fens, that he had now been able to make inquiries from the authorities of several drainage districts, and found that the price of coal delivered at the station to-day was approximately 22s. per ton.

Regarding the comparative running cost of the various types of machinery, the author wished to state that it was very difficult to form a common basis upon which to obtain this comparison. The price of fuel had materially increased during the past few years, even so recently as seven or eight years ago the cost of coal delivered on site was then only $17 \mathrm{~s}$. per ton. From data obtainable and levelling the figures upon the present-day basis of $22 s$. per ton, the following statement might however be taken as fairly approximate :- 


\begin{tabular}{|c|c|c|c|c|}
\hline Type of Plant. & $\begin{array}{c}\text { Fuel per } \\
\text { water-h.p. } \\
\text { per hour. }\end{array}$ & $\begin{array}{c}\text { Cost per } \\
\text { w.h.p. per } \\
\text { hour for } \\
\text { fuel only. }\end{array}$ & $\begin{array}{c}\text { Cost per } \\
\text { w.h.p. per } \\
\text { hour for } \\
\text { attendance, } \\
\text { oil, etc. }\end{array}$ & $\begin{array}{c}\text { Total cost } \\
\text { per w.h.p. } \\
\text { per hour. }\end{array}$ \\
\hline $\begin{array}{c}\text { Steam-driven scoop- } \\
\text { wheels. }\end{array}$ & 11.64 to 6.5 & 1.42 to 0.76 & 0.1 & 1.5 to 0.86 \\
$\begin{array}{c}\text { Steam-driven verti- } \\
\text { cal-spindle horizon- } \\
\text { tal pumps - } \\
\text { Steam-driven hori- } \\
\text { zontal-spindle cen- } \\
\text { trifugal pumps }\end{array}$ & 6.25 & 0.73 & 0.1 & 0.83 \\
\hline
\end{tabular}

When comparing these figures of running cost with those gbtained from large power stations, the author wished to point out again that the small power of the units, the isolation of the stations and the conditions existing, such as did not appertain in other part of the British Isles, must be considered before any true conclusion could be arrived at.

Mr. E. G. Crocker wrote, in further reply to points raised in the discussion and to the communications received, that he would like to draw attention first to the incorrectness of the figures given by Mr. Humphrey regarding the Prickwillow Pump (page 833). The pump discharged 150 tons of water per minute against a maximum head of 16 feet, but the average head against which the pump actually discharged was approximately 11 feet, so that the average volume of water discharged per minute was approximately 220 tons. Taking it at 220 tons, this was equivalent to 164 w.h.p. and the combined efficiency became $54 \cdot 66$ per cent, giving a gross coal consumption of $3.98 \mathrm{lb}$., or, say, $4 \mathrm{lb}$. per w.h.p.hour, which was very different from the $6 \mathrm{lb}$. given by Mr. Humphrey. This $4 \mathrm{lb}$. per w.h.p.-hour included all stand-by losses, and the leakages previously mentioned by the author. He had no records of the other two engines mentioned. 
(Mr. E. G. Crocker.)

With reference to the remarks of $\mathrm{Mr}$. Humphrey on the comparison he (Mr. Crocker) had made of the tender of the Pump and Power Co, with the tenders for an inverted compound steamengine direct coupled to a centrifugal pump, the tender for the Humphrey pump was exactly double that for the steam-engine and centrifugal pump. Mr. Humphrey's statement as to the boiler plant being existent and not included in this comparison was quite correct, but if the cost of the boilers and boiler-house plant were added to the cost of the steam-engine and centrifugal pump, the initial cost of the Humphrey pump was still 50 per cent. in excess, exclusive in both cases of the buildings and foundations; and if the cost of these were added, the deep and extensive foundations necessary for the Humphrey pump brought the cost of its complete installation to more than double that of a modern steam-driven centrifugal pump installation.

From careful study of the Humphrey pump since 1909, he (Mr. Crocker) failed to see where it was so greatly superior to the steam-driven centrifugal pump. The statement in his (Mr. Crocker's) reply was intended to be only a passing allusion, the Humphrey pump not being under discussion, but Mr. Humphrey had brought his pump so prominently forward, and had made such extravagant claims for it in connection with Fen drainage, that he (the author) thought some mention should also be made of some of its disadvantages. With regard to the efficiency, it was only to be expected that a good thermodynamic efficiency would be shown in a similar way to that shown by a gas-engine over a steam-engine, but thermodynamic efficiency was not the only point to be considered in a pumping installation. Mr. Humphrey's claim to low initial cost for the installation could not, he contended, be upheld in view of the actual tender prices. Deep, extensive, and costly foundations were required. Variations in head due to alterations in water-levels of suction and delivery could not be efficiently dealt with, and with the constantly varying water-levels on both the suction and delivery met with in Fen pumping, the total efficiency of the pump would compare very unfavourably with the total efficiency of the centrifugal pump. The water-inlet valves were inaccessible 
owing to their position under water, and their liability to be put out of working order was exceedingly great, due to their design and great number, by weeds, sticks and other debris.

The inlet-, exhaust- and scavenging-valves, being of the automatic spring poppet type and several in number, would be liable to give constant trouble, as had generally been found to be the case with this type of valve. The number of moving parts was greatly in excess of the moving parts in any steam-driven centrifugal pump installation.

No Humphrey pump had as yet been installed sufficiently long enough for any accurate figures to be available regarding its life or maintenance costs. The author doubted that if this pump were installed in the Fens it could show a lower total working cost per annum than a steam-driven centrifugal pump of the same discharging capacity. Every pumping installation must be considered independently for the particular conditions, which it had to fulfil, whether for fen drainage, dock pumping or other work, and for small plants, oil-engines, although not showing such low running and maintenance costs, had often compensating advantages. The flooding of immense tracts of land, with the consequential great financial loss and probable loss of life, in the event of stoppage or failure of a fen pumping plant, precluded the installation by the Commissions of anything in the nature of an experimental plant, apart altogether from the consideration of costs.

The point raised by Mr. Michael Longridge (page 839) with regard to foundations had one objection, namely, that in nearly all cases the extremities of the suction and delivery pipes were founded on hard strata, and fracture of these would be certain under such conditions. The author saw no difficulty in dealing with the foundations of pumping stations in the Fens with present-day knowledge and the use of concrete, either plain or reinforced, in lieu of the brick and timber which had to be used in years gone by. As was well known, in many parts of the country at the present time, structures of much greater size and greater weight per square foot of bearing surface were being erected on far worse foundations, 
(Mr. E. G. Crocker.)

more particularly in connection with large dock undertakings where silt, running sand and other classes of bad foundations were more often met with than otherwise, and the erection of large heavily laden buildings on reclaimed land was an almost everyday occurrence.

With regard to the question of costs per b.h.p. of different types of pumping machinery, raised by Mr. Ellington (page 840), it was not passible to give very accurate figures, as no systematic collection of data was available. From the few figures the author had been able to obtain, he would put them as follows, including interest on capital at 5 per cent., cost of fuel, labour, stores, repairs, and depreciation :-

Per b.h.p. per hour.

Low-pressure beam engines . . . . . 0.62d. to $0 \cdot 70 d$.

Condensing steam-plant $(60$ to $80 \mathrm{lb}$.) . . . $0.4 d$. to $0.42 d$.

Semi-Diesel crude oil-engines . . . . $0.6 d$, to $0.65 d$.

The cost of coal was taken at 22s. per ton and net cost of crude oil at $112 \mathrm{~s}$. per ton. The costs would vary according to the number of hours run per annum, the greater the number of hours the lower the cost per b.h.p., the interest on capital and the depreciation being spread over a greater number of hours. The costs of a Diesel engine over a semi-Diesel engine would show a very small improvement, if any, owing to its greater initial cost. The costs of a modern high-pressure superheated steam-plant working under the same conditions, he should put at $0 \cdot 34 d$. to $0 \cdot 36 d$. per b.h.p. per hour.

With reference to Mr. A. E. Douglass's remarks (page 840), it was, he thought, hardly correct to describe the machinery mentioned in the Papers as obsolete, the Ten-Mile Pumping installation and the Methwold and Feltwell Drainage Board's installation could hardly be so described; they were both new and the latter certainly contained the latest improvements that could be secured for a plant of its type. Many plants were naturally of a rather old pattern, as it was quite impossible for new installations to be laid down every few years; there were however some very old plants, and tlese undoubtedly ought to be removed and replaced by 
modern machinery, not necessarily for the reason that they were old or worn out, but for the sake of economy and the saving of annual expenditure to the Commissions. The object in dealing with Fen drainage in tons per minute as a standard measure was that it was the simplest method; it could be applied to the pumping plant, rainfalls, discharges, etc., whereas foot-pounds had no direct connection with the latter, and in dealing with very large volumes of water in pounds or gallons the figures became far too cumbersome.

When Mr. Douglass referred to ram pumps, the author did not gather if his intention was to suggest that they would be suitable for Fen drainage; in his (Mr. Crocker's) opinion they would be a most unsuitable installation. He inferred (as did Mr. Patchell) that Mr. Douglass suggested central electric generating stations for the distribution of power for driving the scattered drainage pumps. Such a suggestion would not, he was sure, be made by any one having an intimate knowledge of the existing conditions; the area covered would necessitate a large number of central stations and the losses in the long lines of transmission would be enormous. The vast capital expenditure would call for such a high tax upon the land that it could not be borne, and land would thus be forced out of cultivation; the large capital sums spent in the construction of the existing pumping stations would also have to be added to this new capital expenditure, as the total initial capital of such a scheme, and under present existing conditions it was not a feasible commercial proposition. Provided a large inland navigation scheme in connection with the rivers with overhead electric traction were ever to come to maturity, with large works and factories on the river sides to use the power, then such a scheme might become a sound proposition, but this could never be carried out without Government assistance and the provision of the requisite capital by the State.

Mr. F. Sanderson Robins stated (page 851) that for small fens he favoured a plant that could be attended to by an agricultural labourer; this the author considered to be a shortsighted policy. The extra wages paid to a fitter engine-driver 
(Mr. E. G. Crocker.)

would be more than saved every year in the reduction of the running and maintenance costs of the machinery, whereas at present, at many pumping stations, incompetent men were in charge, the plant was run badly and inefficiently, no proper adjustments were made, and when such were attempted, a breakdown usually followed; the makers of the plant then had to send their fitters down, costs of repairs amounted to a large sum, and the manufacturers of the installation generally were blamed. The same remarks applied to the boiler-house, where many men had no knowledge of the care and treatment of boilers, and coal was burnt most wastefully, thus adding considerably to the running costs.

The neglect of plant during the summer and idle times was one for which the engineer to the Commissions should be blamed, but in some places there was no engineer and the plant was left to the labourer driving it. The remedy for this unsatisfactory state of affairs lay primarily with the engineer to the Drainage Commission, and if his advice were not followed, the onus of responsibility would be transferred from him to the Commissioners.

The author was in favour of high-pressure water-tube boilers, high pressures being necessary to economy, and the quick steaming of a water-tube boiler was also a distinct advantage. He believed there was no such boiler plant in the Fens, but it could only be a matter of time when such would be installed and the advantages of the efficiency of high-pressure superheated steam secured. The installation of duplicate plant he considered to be essential in any but the smallest fens. With a duplicate installation, one set could deal with the pumping under normal conditions, the other set being only run in flood times and as occasion might demand; greater economy was in this manner obtained over the running of one large plant continuously at half to one quarter load. 'The author did not consider belt-drives to be advisable even on bad foundations; they must be long to be efficient, entailing much larger buildings with this added weight on the bad foundation. The extra cost of large buildings could be better expended on increased cost of foundations, though the author's experience was that the total 
cost of the belt-driven installation would exceed the direct-coupled, however bad the foundations might be.

Mr. Arthur Titley, Mr. M. Holroyd Smith and Mr. C. Humphrey Wingfield all regarded the scoop-wheel, if properly designed, as efficient for low lifts. The scoop-wheel, however, became inefficient directly there was any material alteration in water-levels at suction and delivery. Before and at the start of a flood the scoop-wheel would work well, the suction water-level being that for which the wheel was designed and the delivery water-level normal. At the middle of a flood the suction water-level bad jumped up, the river into which the water was delivered having probably risen 3,5 , or more feet, and the ladles were drowned by the suction water and the head was too great. Towards the end of a flood the suction water had been lowered so that there was very little water for the ladles to get hold of, but the river would be still very high. Under these two latter conditions the scoop-wheel became very inefficient, and, generally speaking, it could not efficiently perform the work it was called upon to do in connection with Fen drainage; present conditions were also much against the scoop-wheel, the sinking of the Fens making the lift too great. There could be no doubt but that they could in all cases be very advantageously supplanted by centrifugal pumps.

Mr. W. H. Patchell drew attention (page 850) to the importance of the study of geology, and this was a matter to which all engineers should attach great importance, perhaps more especially in connection with Fen work. With reference to the rainfalls, the figure given was obtained by averaging the monthly returns of the Royal Meteorological Society over the drainage basin for the period under review. On 26th August 1912, $4 \frac{1}{2}$ inches of rain fell in 24 hours, the whole of this having to be pumped by the Prickwillow engines, whilst at Thetford 6 inches of rain fell during the same period. The usual provision for Fen pumping stations was a maximum of $\frac{1}{4}$-inch of rain over the whole drainage area of the Fen per 24 hours to be discharged at the maximum lift; but if there were any considerable soakage through the river banks or high land water coming into the Fen, this amount should be increased. 
(Mr. E. G. Crocker.)

Mr. M. Holroyd Smith raised several points (page 852) about which much could be written. The remarks on pumping stations were not very specific, but appeared to imply that mechanical engineers put down pumps to pump water which could be naturally discharged to the sea, and such was a very obvious error. All water which could be drained naturally into the rivers was so done, and large sums had been expended on the construction of catch-waters to drain the water from the high lands and so prevent it coming into the Fens.

The protest made against the practice of cutting the weeds and leaving them to float out to sea was an old one, usually made by those who used the rivers for their own enjoyment and contributed nothing towards the maintenance thereof. Pleasure craft paid nothing to the river authorities, yet their owners were the first to call for improvements; this was one point requiring remedy, and the levying of tolls on pleasure craft was one which most boating people would be glad to see enforced as soon as the authorities had powers to do so. He would suggest that Mr. Holroyd Smith should go to King's Lynn, at the mouth of the River Ouse, some few days after weed-cutting had been executed in the rivers, and he would then be convinced that the bulk of the weeds cut did not rot and sink in the rivers but were carried out to sea. Some small amount no doubt collected on the points and obstructions and never got so far as the sea, but this was really a very small percentage of the whole. The cost of pulling out all the cut weeds from the rivers would be great, and, in the author's opinion, quite an unnecessary expenditure. The odours which at times arose from the rivers were due to the large amount of crude sewage and partly-treated sewage effluent which was discharged into the rivers from all the towns and villages in the River Ouse basin. The increase of fish life was a proof of the cleanliness of the rivers, but surely it could not be suggested that drainage and navigation authorities should be given powers to expend money raised by taxation for drainage and navigation purposes for the improvement of the fishings for the benefit of anglers who contributed nothing. The portion of the river referred to as being in such a bad state was mentioned 
in the Paper (page 814), and this part of the river was under no river authority. Some portion of it was owned and controlled by a private individual, and other parts he believed the County Councils claimed as coming within their jurisdiction; but immediately the question arose as to the expenditure of money on improvements, they generally repudiated their liability and stated that they had no powers to spend money on such work.

The remarks as to the "caprice" of sluice-keepers had some little ground, and was only what could be expected; the men so employed were only paid $8 s$. to $12 s$. per week, they were often old men, and frequently of a low intellectual order, as no other class of labourer could be obtained at the wages paid. This condition of things, with no competent engineer controlling the river, called for remedial measures, and was a strong argument in favour of the whole of the rivers in a drainage basin being placed under the control of one authority. This was a most urgent matter, and one absolutely necessary before any real progress could be made in the improvement of inland navigation and of drainage. Sluice-keepers should not be left to work the sluices on their own responsibility, but should all be connected by telephone with the chief engineer's office and only act in accordance with the instructions received from that office.

There were many difficulties to be contended with in the formation of a Rivers Controlling Authority, but these were not insurmountable. It was a matter for regret that the Honourable Bedford Level Corporation had from time to time had their powers curtailed, through the division of the different levels, so that they did not now control the same length of waterway as formerly; all the great works in the Fens were carried out by this Corporation and several of its present members had life-long experience of navigation and drainage matters, so that the formation of this Corporation into the controlling authority over the whole of the rivers and waterways in the River Ouse basin would probably be the most beneficial for all interested. It would be necessary for the Corporation to be entirely reconstituted, and for it to be given wide powers of control, and also very wide powers for dealing 
(Mr. E. G. Crocker.)

with finance and the raising of the necessary funds to execute the improvements so much required.

The uplands and all lands which drained into the rivers and so to the sea, and which up to the present had not contributed to such drainage, should bear their share of taxation as well as the lower and fen lands. The granting to the new authority of means of securing adequate funds was essential for its successful working. 
DRAINAGE OF THE RIVER OUSE BASIN. Plate 17.

Fig. 2. Faggoting Banks at Eau Brink Cut.

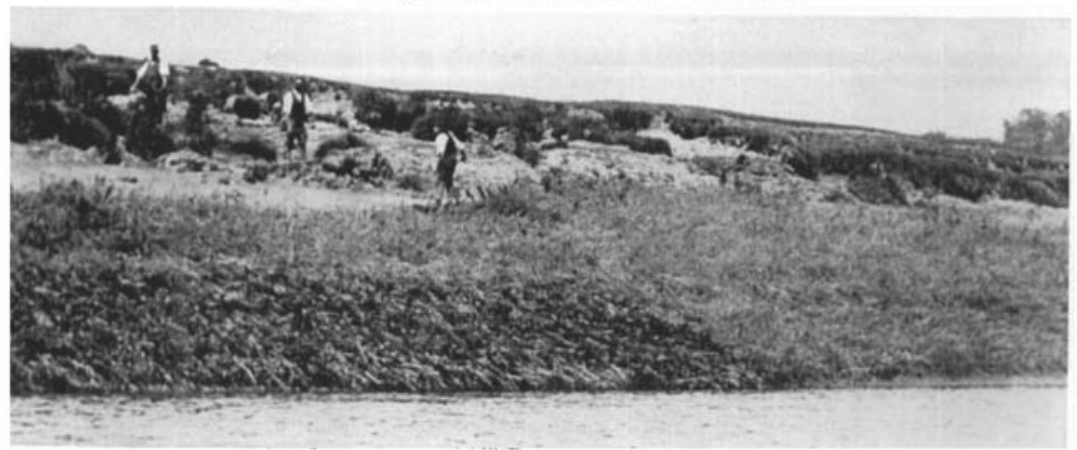

Fig. 3. Free Bridge, King's Lynn, 1873.

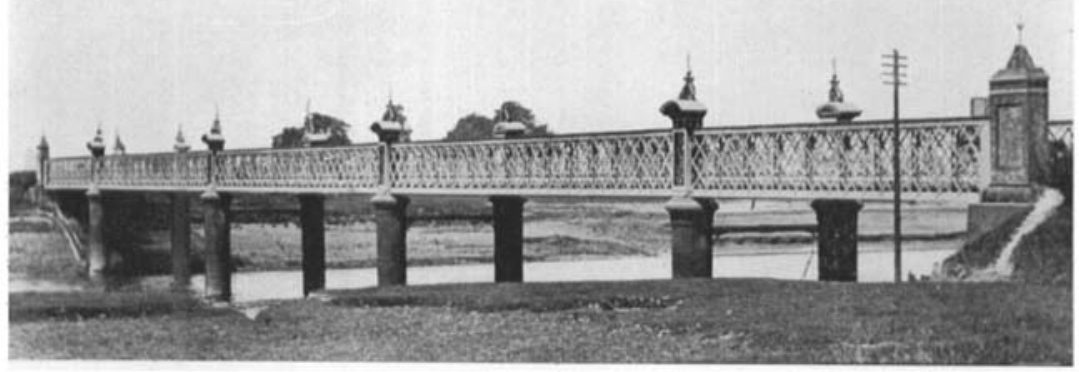

Denver Sluice.

Fig. 6. From Sea side at Low Water Neap Tide.

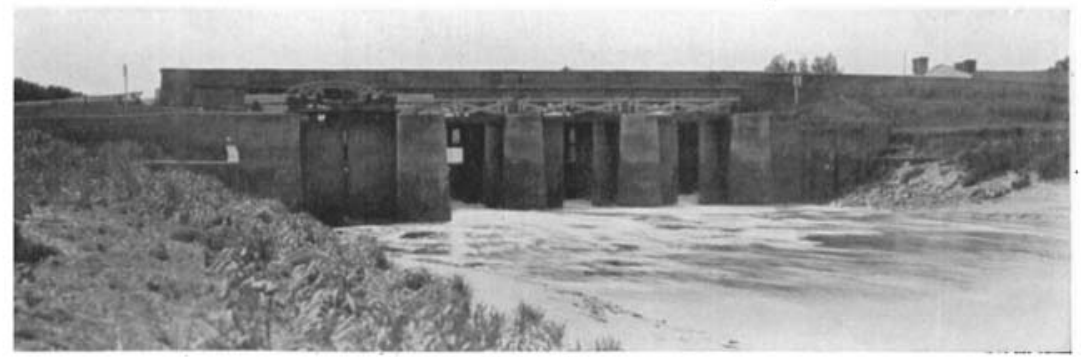

Fig. 7. From River side.

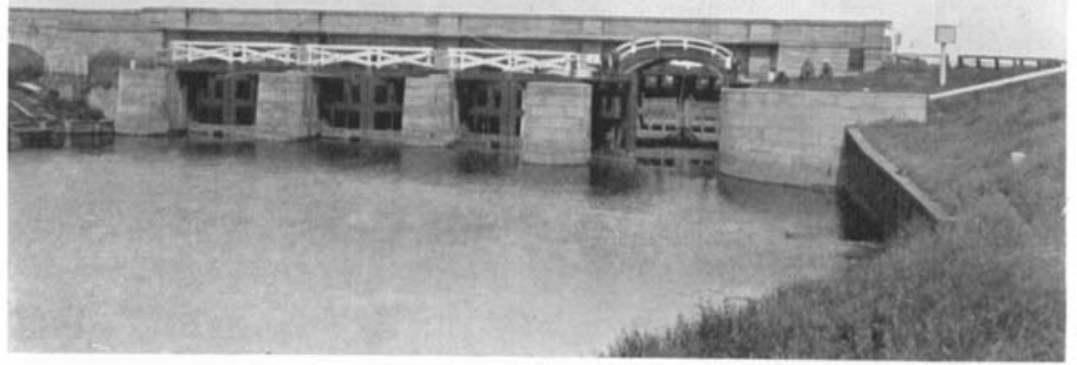

Mechanical Engineers 1913. 
DRAINAge OF THE RIVER OUSE BASIN. Plate 18. Swaffham Lock.

Fig. 8. New Doors erected in place. Fig. 9. Dried to permit repairs to Sills.

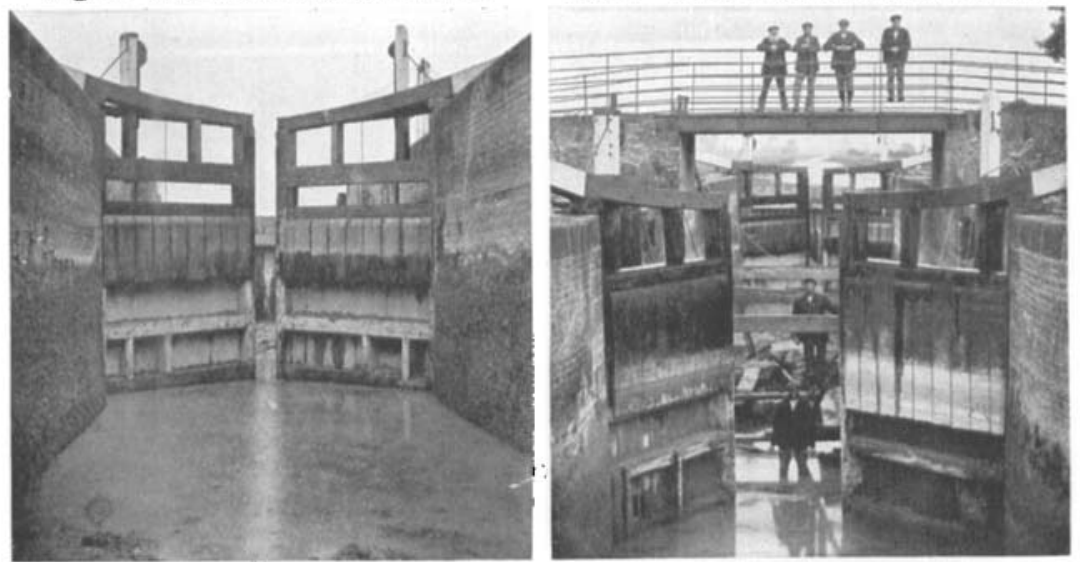

Fig. 10. Roswell Hill Quarry.

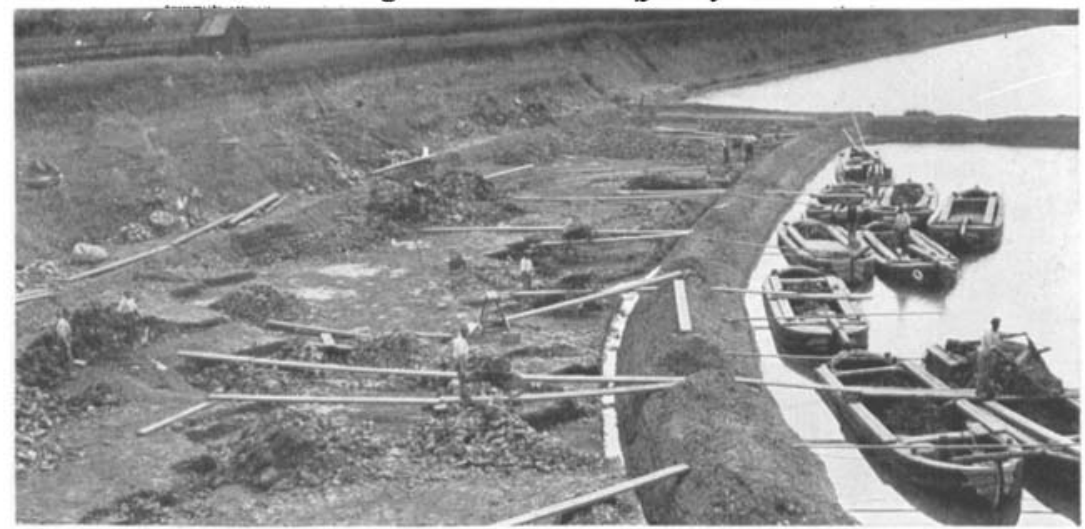

Fig. 12. Mildenhall Fen Commission, River Lark Bank.
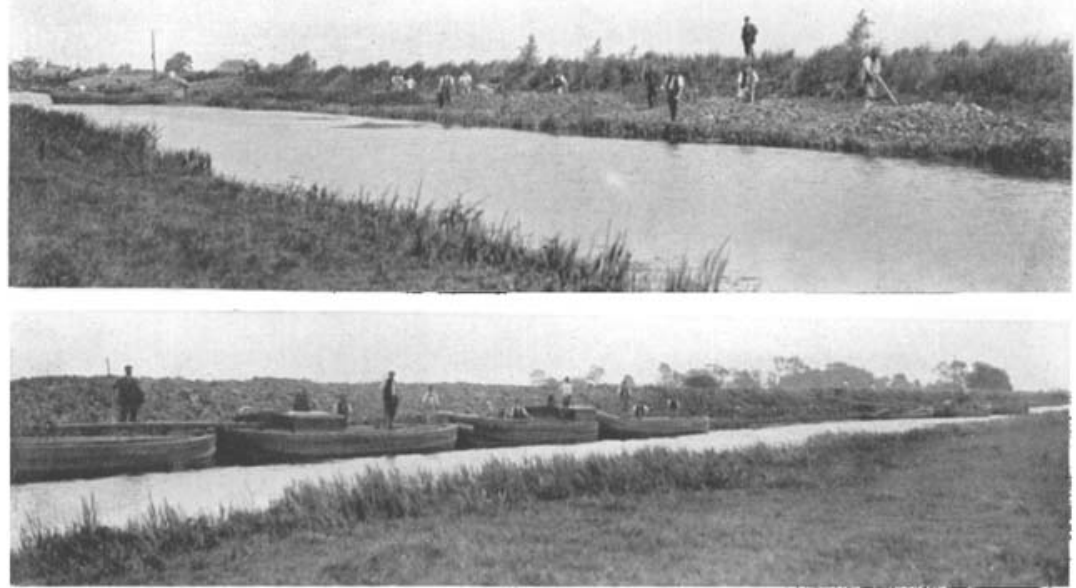

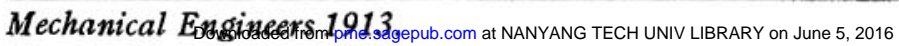




\section{DRAINAGE OF THE RIVER OUSE BASIN. Plate 19. Hockwold Bank.}

Fig. 13. River flowing into Fen.

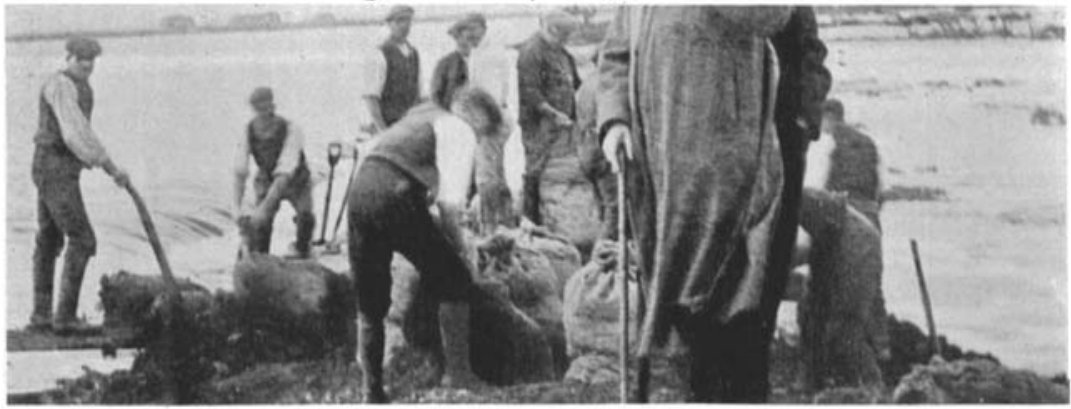

Fig. 14. Temporary Sand-bag Bank completed and showing deep hole scoured out where original bank existed.

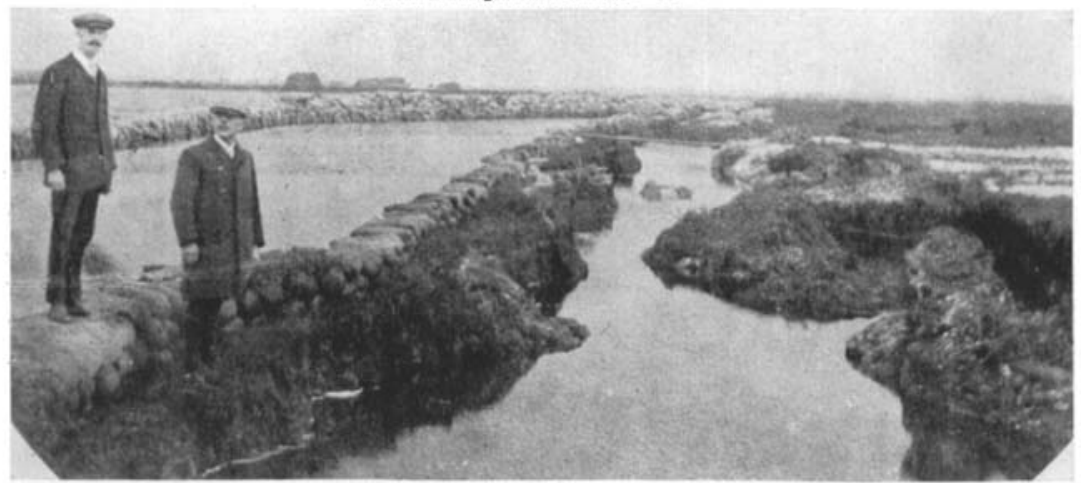

Fig. 15. Showing completed temporary Bank.

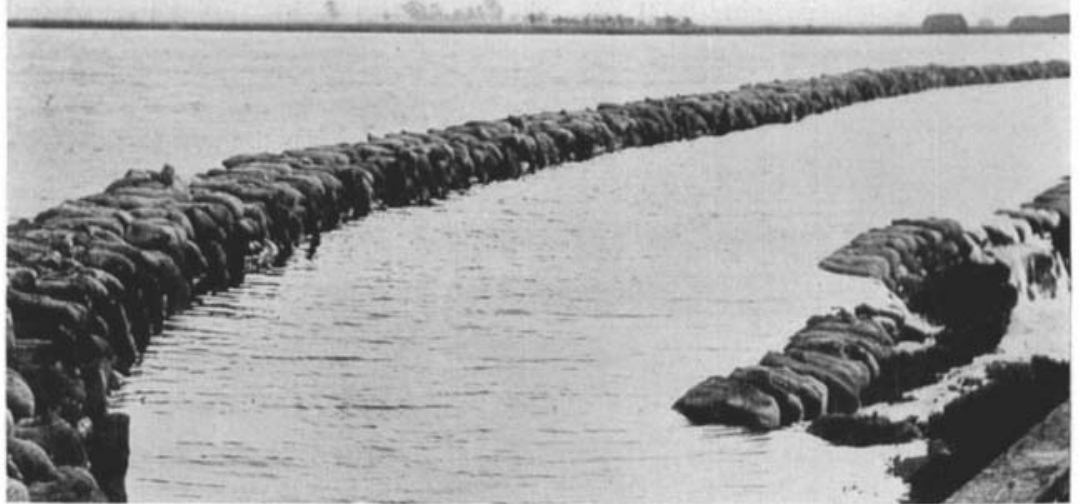

Fig. 16. New Bank completed.

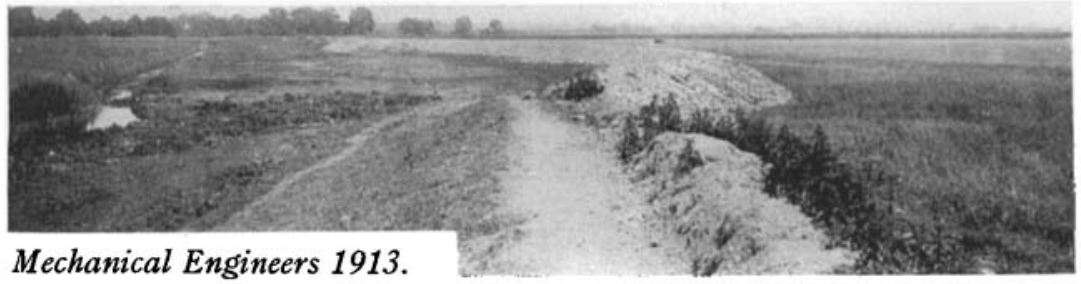

Downloaded from pme.sagepub.com at NANYANG TECH UNIV LIBRARY on June 5, 2016 
DRAINAGE OF THE RIVER OUSE BASIN. Plate 20. Fig. 17. Dredger at work in River West.
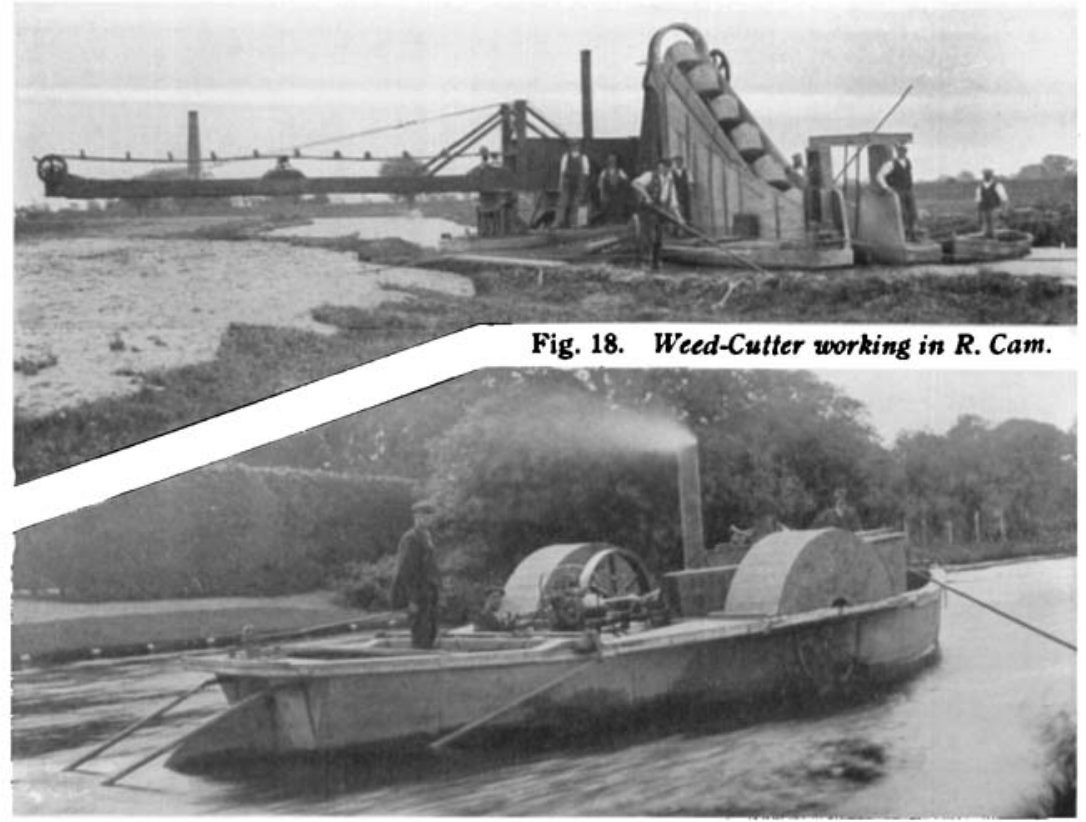

Fig. 21. Barway Mill.

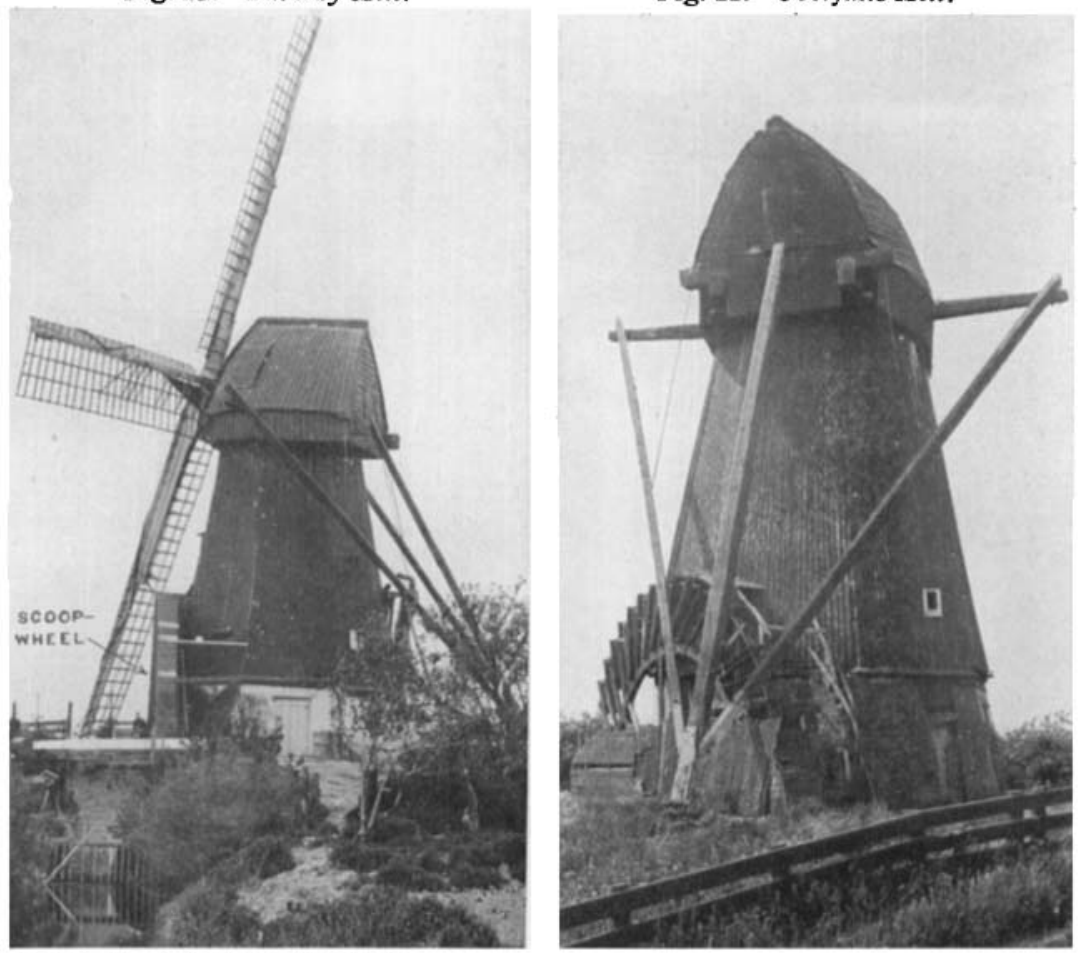

Mechanical Engineers 1913.

Downloaded from pme.sagepub.com at NANYANG TECH UNIV LIBRARY on June 5, 2016 
DRAINAGE OF THE RIVER OUSE BASIN. Plate 21. Middle Fen.

Fig. 23. Soham Tunnel Mill.

Fig. 24. Isleham New Mill.
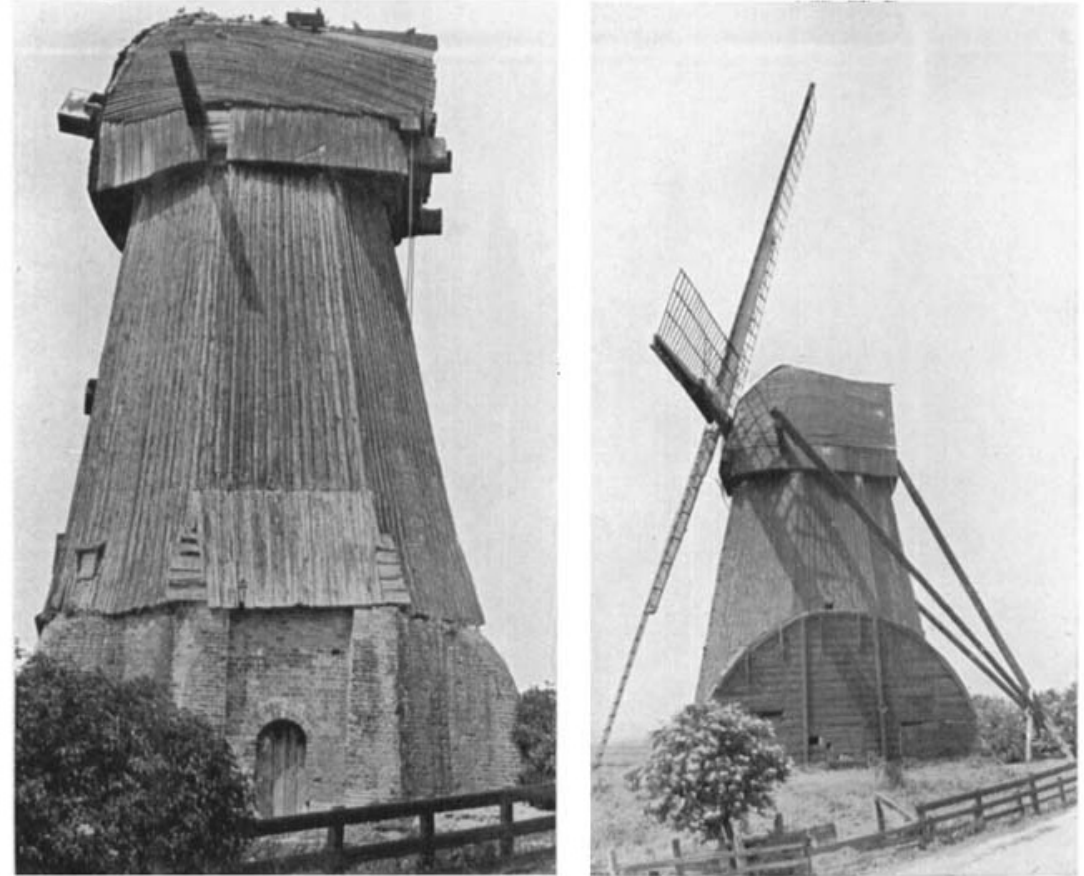

Methwold and Feltwell Drainage Board.

Fig. 25. New Pumping Station.

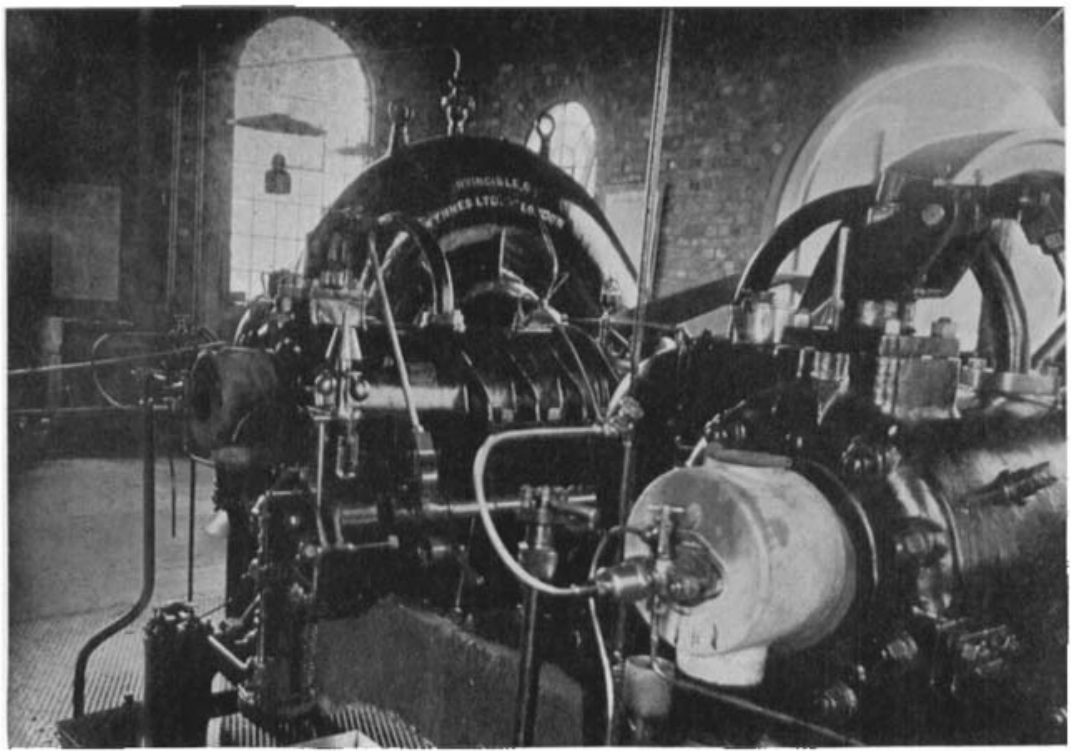

Mechanical Engineers 1913.

Downloaded from pme.sagepub.com at NANYANG TECH UNIV LIBRARY on June 5, 2016 
DRAINAGe OF THE RIVER OUSE BASIN. Plate 22.

Feltwell New Fen Commission.

Fig. 26. Southery Scoop-Wheel and Engine.
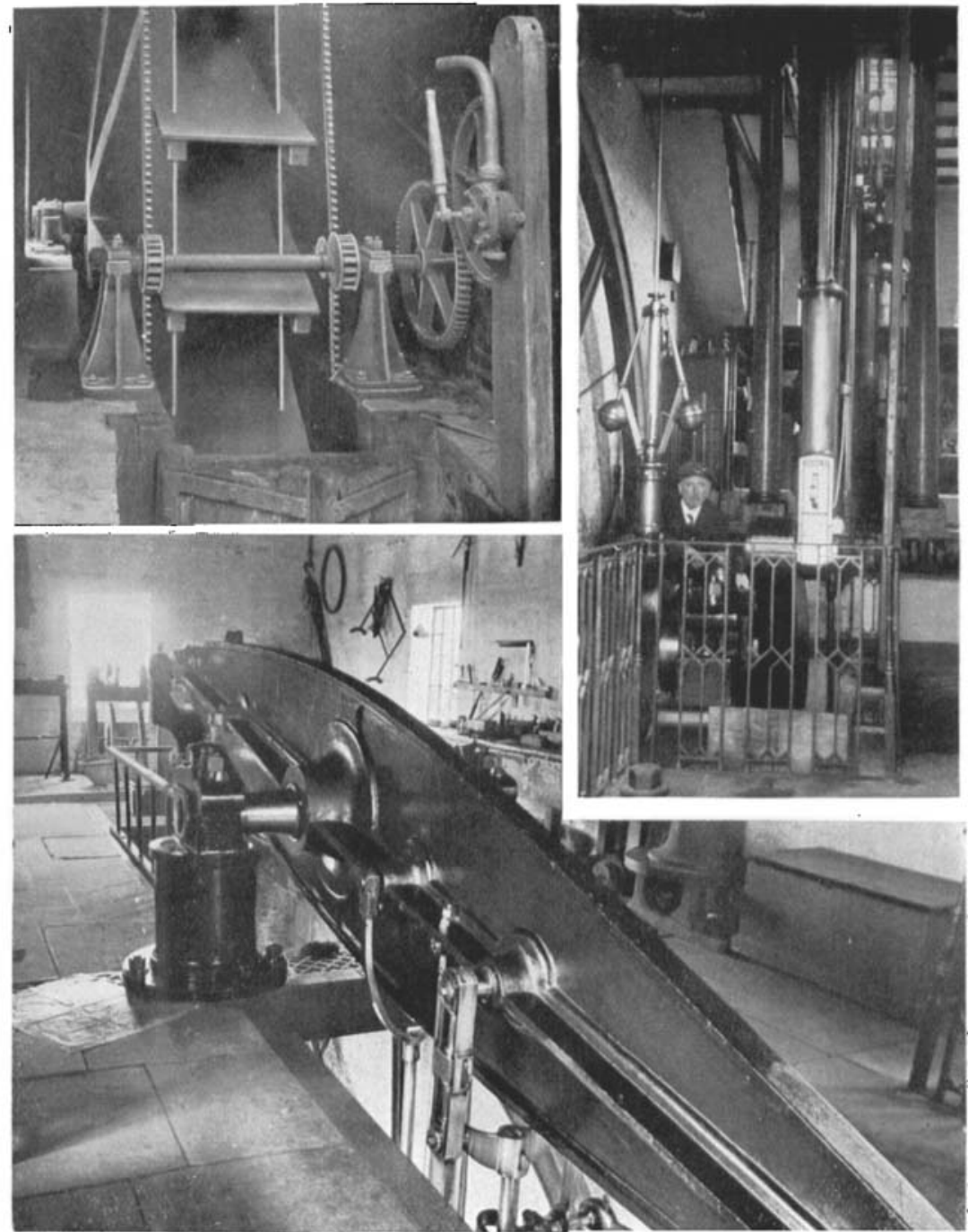

Fig. 28. Fen Farm House showing settlement.

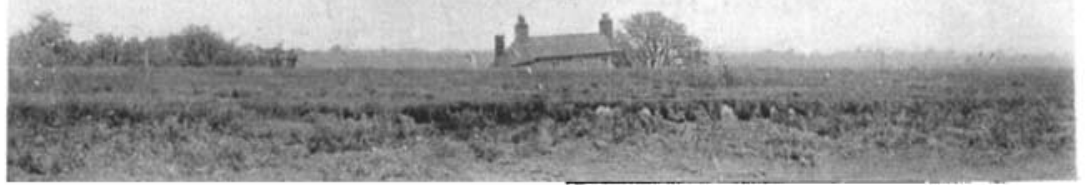

Mechanical Engineers 1913.

Downloaded from pme.sagepub.com at NANYANG TECH UNIV LIBRARY on June 5, 2016 
Fig. 31.

Mildenhall Fen Commission.

Fig. 32.

Pl. 23.

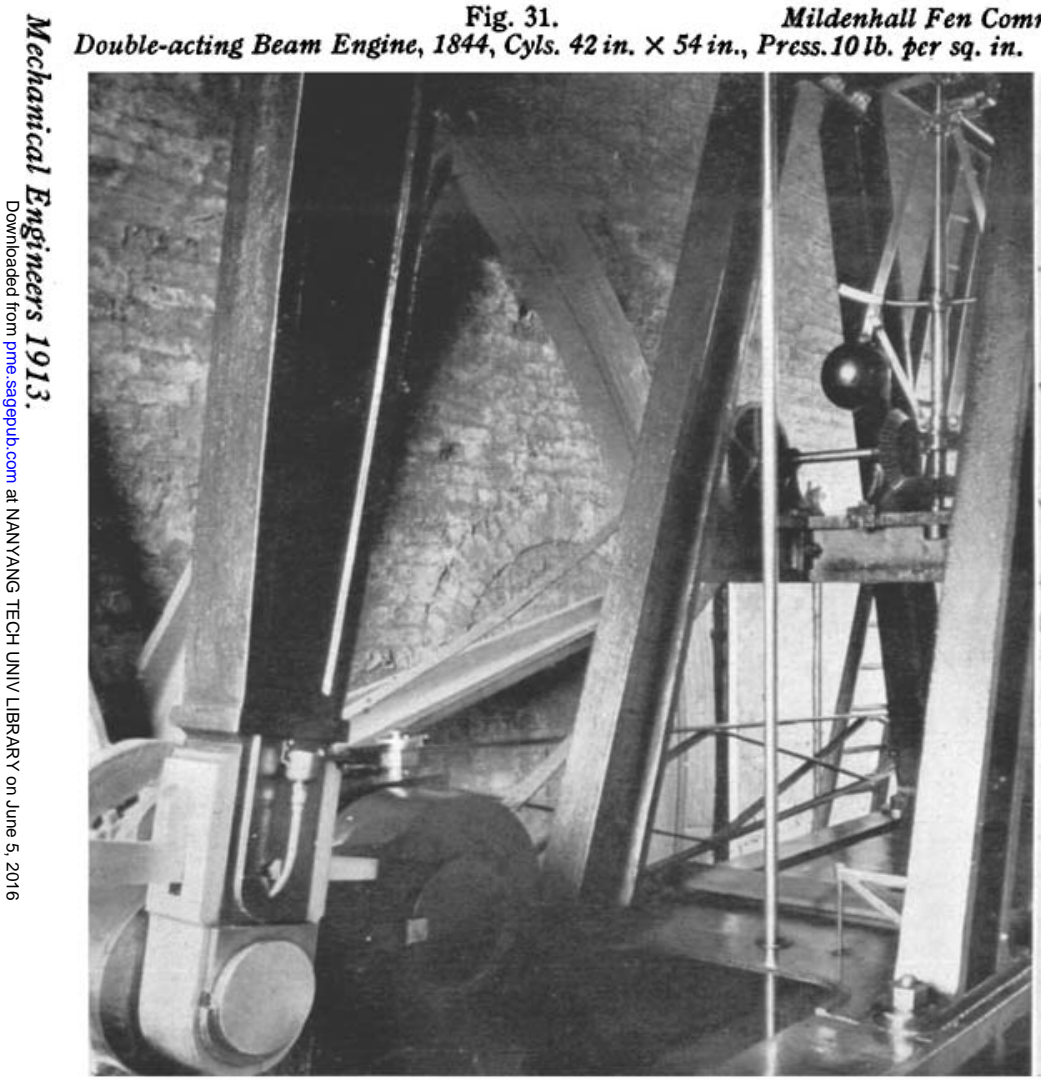

Scoop-Wheel, $32 \mathrm{ft}$. diam. geared $5 \frac{1}{2}$ to 1, Lifting 5-12 ft.

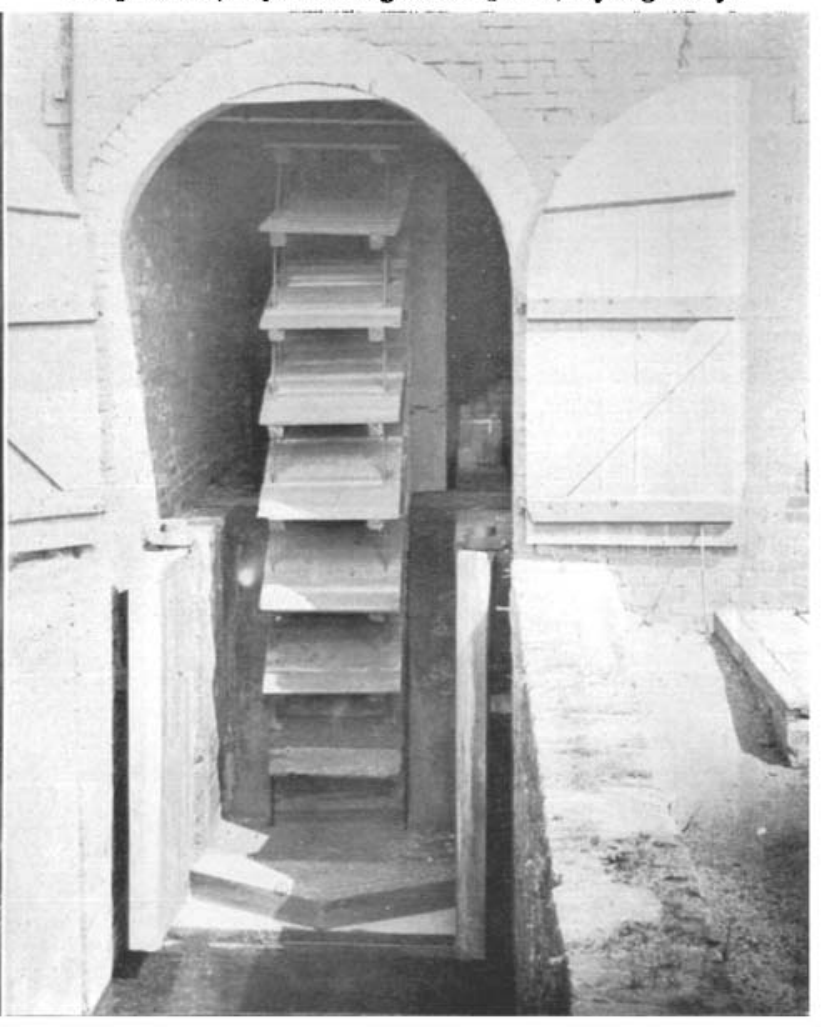

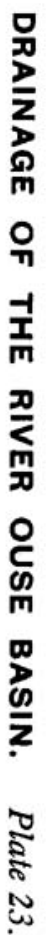

